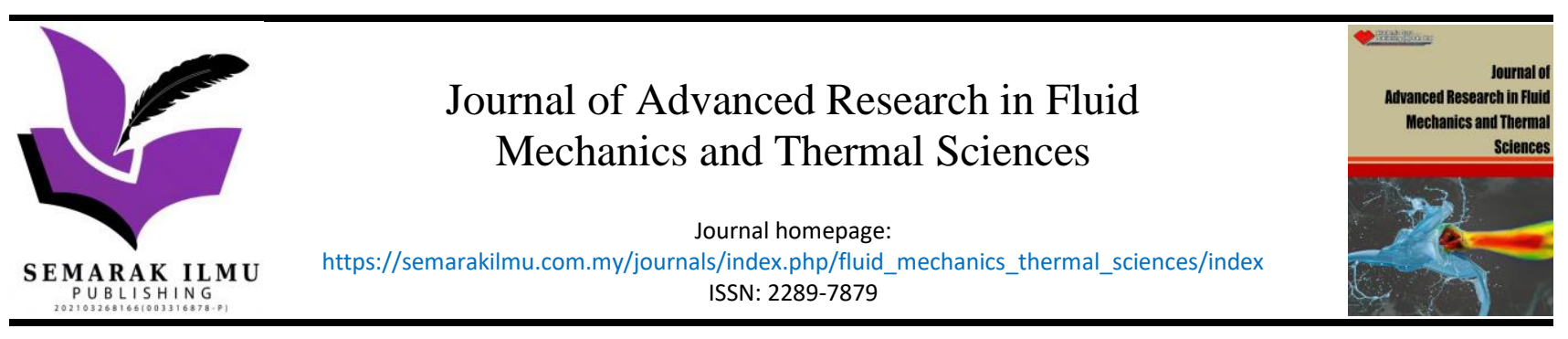

\title{
Fluid and Structure Analysis of Wind Turbine Blade with Winglet
}

\author{
Osama A. Gaheen ${ }^{1}$, Mohamed A. Aziz ${ }^{2,}{ }^{,}$, M. Hamza ${ }^{3}$, Hoda Kashkoush ${ }^{4}$, Mohamed A. Khalifa ${ }^{1}$ \\ Institute of Aviation Engineering and Technology, Giza, Egypt \\ College of Engineering, Suez University, Suez, Egypt \\ Mechanical Engineering Department, South Valley University, Egypt \\ Mechanical Design and Production Department, Cairo University, Egypt
}

\section{ARTICLE INFO ABSTRACT}

Article history:

Received 10 July 2021

Received in revised form 29 October 2021

Accepted 5 November 2021

Available online 11 December 2021

\section{Keywords:}

Wind Turbine; Blade Design; Winglet Configuration; Surface Response; Structural Analysis; Numerical Simulation

\begin{abstract}
One of the succeeded methods to enhance the performance of horizontal axis wind turbine (HAWT) is an attaching a winglet to the blades tip. The current paper study the effect of four key parameters that are used to describe the winglet on the performance of wind turbine which are winglet height $H \% R$, cant angle $\theta$, twist angle $\beta$, and taper ratio $\Lambda$. A five design cases for each geometric parameters were numerically investigated using computational fluid dynamics (CFD) by ANSYS18.1 software, which totally give a twenty different response. A validation of present computational model with reference experimental results successfully carried out with maximum inconsistency of $3 \%$. A mathematical correlation was established from the CFD results and being used in predicting the turbine power for the different winglet geometric parameters. From CFD and mathematical correlation response, the effect of $H$ and $\theta$ were greater than $\beta$ and $\Lambda$ on the turbine power. The epoxy E-glass unidirectional material was selected for current study to investigate the effect of winglet on blade structure. The power increases by $2 \%$ to $30 \%$ due to adding winglet to a wind turbine blade. The maximum power increment corresponds to the design case of W6 with $\mathrm{H}=8 \% \mathrm{R}, \theta=30^{\circ}, \beta=3^{\circ}$, and $\Lambda=0.8$. Form the structural analysis the addition of winglet changes the stress distribution over the blade, increasing stresses at the blade root, and achieved the transfer of the maximum deformation from the blade tip to the winglet tip.
\end{abstract}

\section{Introduction}

Nowadays, discovery of alternate clean energy resources is of great interest due to different aspects related to regular fossil fuel such as emissions, acid rains and global warming problems beside expected exhaust of the fossil fuel. One of the most valuable alternatives is the wind energy. It expected to be elaborate in producing up to $20 \%$ of global electricity production by 2030 [1].

Numerous researchers have studied the aerodynamic characteristics of HAWT in order to explain the extraction of energy by rotor. The flow around the rotor blade contains much complex interactions due to vortex generation and produced turbulence. Studying such problem in experimental mean needs equipment that provided detailed measurement with accurate and

\footnotetext{
* Corresponding author.

E-mail address: mohamed.aziz@suezuni.edu.eg
}

https://doi.org/10.37934/arfmts.90.1.80101 
sensitive sensors. The validated numerical simulations considered a better alternate to explain the flow characteristics. The most reliable approaches that used to investigate aerodynamics forces are the Computational Fluid Dynamics (CFD) and the Blade Element Momentum (BEM) theory. In BEM the blade was dividing into number of elements. The BEM solves number of equations at each section depending on experimentally measured lift and drag coefficients related to the airfoil available in literature. Airfoils used in the design of practical HAWT to convert the kinetic energy within the wind into valuable energy. The sectional blade consists of the two-dimensional airfoils. These airfoils considered the main source for producing lift and drag forces by asset of pressure variations between its pressure, and suction surfaces [2]. Although BEM is a simple method, but it is limited to certain wind speed after that it fails to predict the acquired torque [3]. The reason as referred by the researchers is due to tip losses that not predicted using the BEM. There are many correction factors regarding tip loss that made BEM more realistic [4].

CFD becomes a common mean on simulating different flow field problems. CFD has been considered a reliable tool to investigate the performance characteristics of the HAWT with the ability of capturing the tip vortices and its related characteristics. Recently, many researches have studied the performance enhancement of HAWT by investigating the aerodynamics of blades. The vortices near the blade tip are of great effect on reducing lift force and increasing the induced drag. The key role of the winglet is then to reduce the tip vortices effect by moving the vortices far from the plane of rotation. The winglet may be a good load carrier that decreases the spanwise flow. It works on diffusing the tip vortex distant from the rotor plane reducing the downwash and thus the induced drag of the blade [5].

Johansen and Sørensen [6] has numerically analyzed the effect of different winglet parameters such as curvature radius, height, sweep and twist angles on the aerodynamic performance of the wind turbine, they have concluded that adding winglet to the conventional blade increases the power up to $2.8 \%$ due to the increase of winglet height by $4 \% \mathrm{R}$. Johansen and Sørensen [7] performed other study using CFD to investigate five winglets with different twist distribution and camber at constant height $1.5 \% R$ and cant angle $90^{\circ}$. They found that the power increased around $0.6 \%$ to $1.4 \%$ for wind speeds larger than $6 \mathrm{~m} / \mathrm{s}$.

Gupta and Amano [8] have investigated the performance of wind turbine blade with winglet, two key parameters are taken in the consideration of the design of winglet, as a result of adding winglet to the straight wind turbine blade, $20 \%$ increase in the generated power with winglet height $4 \%$ of rotor radius, and cant angle of $45^{\circ}$. Satwika et al., [9] have attained an experimental study on HAWT with winglet to increase the lift force developed by each airfoil of the blade, the results indicate that adding winglet to the blade increase the starting torque in case of low tip speed ratio. Imamura et al., [10] have investigated the numerical analysis of the wind turbine blade with winglet, and calculated that the power coefficient is increased by adding winglet duo to smaller installation angle of the winglet that result from the increase of the circumferential component of the lift.

Elfarra [11] has studied the performance of HAWT with winglet, bending of the winglet is towards the suction side of the blade and concluded that the generated power increased to $9.5 \%$ comparing with the straight blade. Congedo and De Giorgi [12] concerned to improve the rotor performance using CFD by studying the effect of downwind winglet height and curvature radius, they concluded that the power increased by $1.7 \%$ when the winglet height increased by $25 \%$. Ali [13] has experimentally and numerically analyzed the effect upwind and downwind winglet configurations, concluded that in the case of upwind winglet, the power coefficient increased up to $6.67 \%$, and in case of downwind winglet, the power coefficient reduced by $8.89 \%$. Gaunaa and Johansen [14] has numerically concerned to determine the maximum aerodynamic efficiency of wind turbine rotors 
with winglets, they found that, at the same length of winglet, downwind winglet (bending to suction side) is more effective than upwind winglet (bending to pressure side).

During wind turbine operation, the blade may be deformed as result of the generated aerodynamic loads. The deformed blade had led to new flow field characteristics on the blade and extra load deviation [15]. The interaction between fluid force and structural deformation existed once pressure has created on the structure that successively causes structure distortion counting on material of the blade [16]. It is then necessary to better select the blade material that could withstand and resist the applied aerodynamic loads. The common material being used in the industry of the small wind turbines blades includes wood, metals, glass fiber reinforced polymers, carbon fiber reinforced polymers, natural fiber reinforced polymer, and Nano-composites [17]. Fluid Structure Interaction (FSI) problem is often too complex to solve analytically, so they can be analyzed by means of numerical simulation, therefore, aerodynamics load and structure components are required to FSI model to investigate the blade performance [18]. Many researchers have considered the FSI of the HAWT [19-21].

Wang et al., [15] have calculated the aerodynamic loads using a CFD model, and also have determined the blade structural responses using a FEM model on a $1.5 \mathrm{MW}$ HAWT blade. The results have indicated the blade tip flap-wise deflection within $(1.785 \mathrm{~m})$ at $12 \mathrm{~m} / \mathrm{s}$ wind speed. The maximum tensile and compressive stresses have been checked and compared with the material strength limits. Zhang et al., [22] have numerically simulated the FSI using ANSYS. The simulations have indicated increase of wind shear effect on both displacement and stresses response curves. The nonlinear increases of the displacement of blade airfoil have been achieved along the blade span. The maximum displacement has been achieved at the blade tip. The maximum stress located at the mid span of the blade. MacPhee and Beyene [23] have numerically studied the FSI of symmetric blade subjected to variable loading. The study suggested some geometrical morphing to improve lift to drag ratios. They have used FSI program included three open source programs, (GMSH, ELMER, and XFOIL).

The current paper aims to investigate the winglet effect on both aerodynamics and the structural characteristics of the HAWT blade using CFD and FEM in ANSYS 18.1 software. The BEM theory has been used to design a HAWT. The CFD software was validated and provided an accepted percentage of error. The numerical simulations have investigated the performance of straight blade at the design conditions. The simulations were then conducted to the blade with winglet. Then the tip deformation and root stresses were investigated.

\section{Theoretical and System Modeling Analysis}

\subsection{Rotor Blades Configuration}

\subsubsection{Conventional blade design}

BEM is the basic theory of wind turbine blade design. The theory combining between blade geometry and momentum theory, at each blade element, the theory solves a set of equations based on balancing the axial momentum and angular momentum. The theory predicts the element forces based on experimentally obtained lift and drag coefficients from two-dimension cascade measurement in wind tunnel available in literature. The design of three-bladed rotor was conducted using BEM theory. The NREL's S809 rotor airfoil was considered for the blade while the Reynolds number equals $5 \times 10^{5}$. The designed rotor blade parameters are presented in Table 1 .

The chord lengths and pitch angles distribution were calculated by using the following equations: 
Chord distribution for each element.

$\mathrm{C}_{\text {schmitz(i) }}=\frac{1}{Z} * \frac{16 \pi r_{i}}{\mathrm{CL}} *\left(\frac{\sin \phi 1}{3}\right)^{2}$

where $\left(C_{L}\right)$ is the lift coefficient and $(r)$ is local radius of blade

\section{Table 1}

Rotor design parameters according to blade element momentum theory

\begin{tabular}{llll}
\hline Name & Symbol & Value & Unit \\
\hline Rated power & $P_{\text {rat }}$ & 50 & watt \\
Rated wind speed & $\mathrm{V}_{\text {rat }}$ & 8 & $\mathrm{~m} / \mathrm{s}$ \\
Design tip speed ratio & $\lambda$ & 4 & - \\
Blade radius & $\mathrm{R}$ & 35 & $\mathrm{~cm}$ \\
Number of blades & $\mathrm{Z}$ & 3 & blade \\
Design angle of attack & $\alpha$ & 7 & degree \\
Rated rotor speed & $\omega$ & 91.43 & Rad/s \\
Power coefficient & $\mathrm{C}_{\mathrm{p}}$ & 0.45 & - \\
\hline
\end{tabular}

The subscript, $\mathrm{i}$ is the number of elements along the blade and

$\phi_{1}=\operatorname{Tan}^{-1}\left(\frac{R}{\lambda r_{i}}\right)$

Relative wind angle $\phi_{\mathrm{i}}$ for each element

$\phi_{\mathrm{i}}=\frac{2}{3} * \phi_{1}$

pitch angle,

$\beta_{i}=\phi_{i}-\alpha$

By solving these equations, the chord lengths and pitch angles distribution can be obtained as shown in Table 2, The three-dimensional view of the blade geometry, which was generated using Ansys Design Modeler software, is shown in Figure 1.

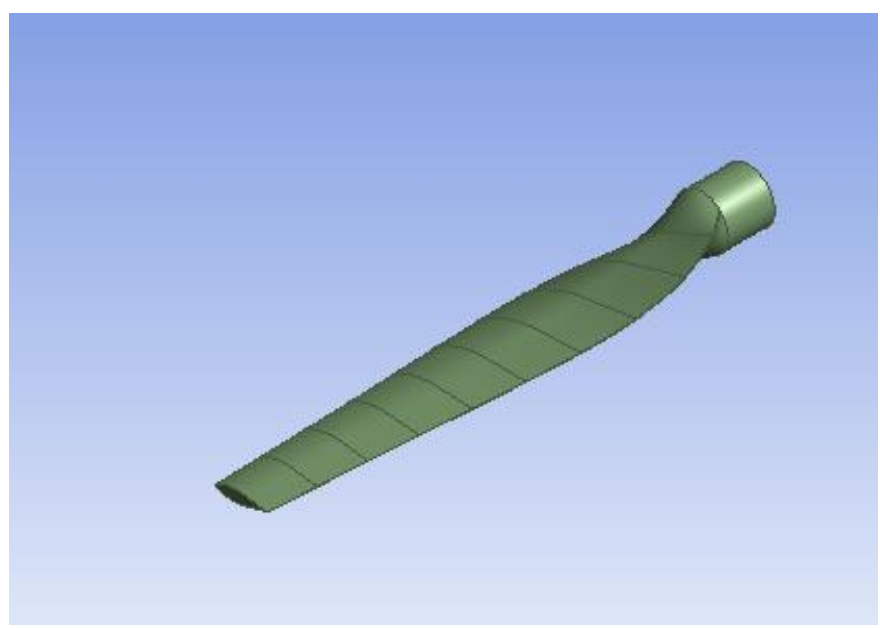

Fig. 1. Three-dimensional rotor blade 
Table 2

The chord lengths and pitch angles distribution

\begin{tabular}{llll}
\hline Section & $r / R$ & Chord length $(\mathrm{m})$ & Pitch angle (degree) \\
\hline 1 & 0.1 & 0923 & 35.2 \\
2 & 0.2 & 0.107 & 27.23 \\
3 & 0.3 & 0.098 & 19.54 \\
4 & 0.4 & 0.085 & 14.33 \\
5 & 0.5 & 0.073 & 10.71 \\
6 & 0.6 & 0.064 & 8.08 \\
7 & 0.7 & 0.056 & 6.1 \\
8 & 0.8 & 0.050 & 4.57 \\
9 & 0.9 & 0.045 & 3.35 \\
10 & 1 & 0.041 & 2.36 \\
\hline
\end{tabular}

\subsubsection{Winglet design}

Winglet is a small device at the blade's tip. That is used to reduce the induced drag by eliminating turbulence [24]. It was used successively in upgraded airplane's wing to improve the aerodynamic performance like lift to drag ratio by scattering the shed wingtip vortex [25]. However, another drag produces by the added winglet due to winglet shape and increased in surface area. The main characterizing parameters used to describe and design the winglet are height $(H)$, twist angle $\beta_{t}$, cant angle $\theta$ and taper ratio $\wedge$ as shown in Figure 2 .

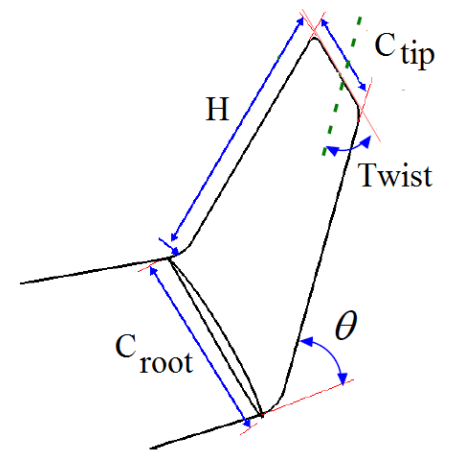

Fig. 2. Definition of geometrical parameters describing the winglet [26]

Blade geometry with winglet is generated also in Design Modeler. Figure 3 shows the blade with winglet.

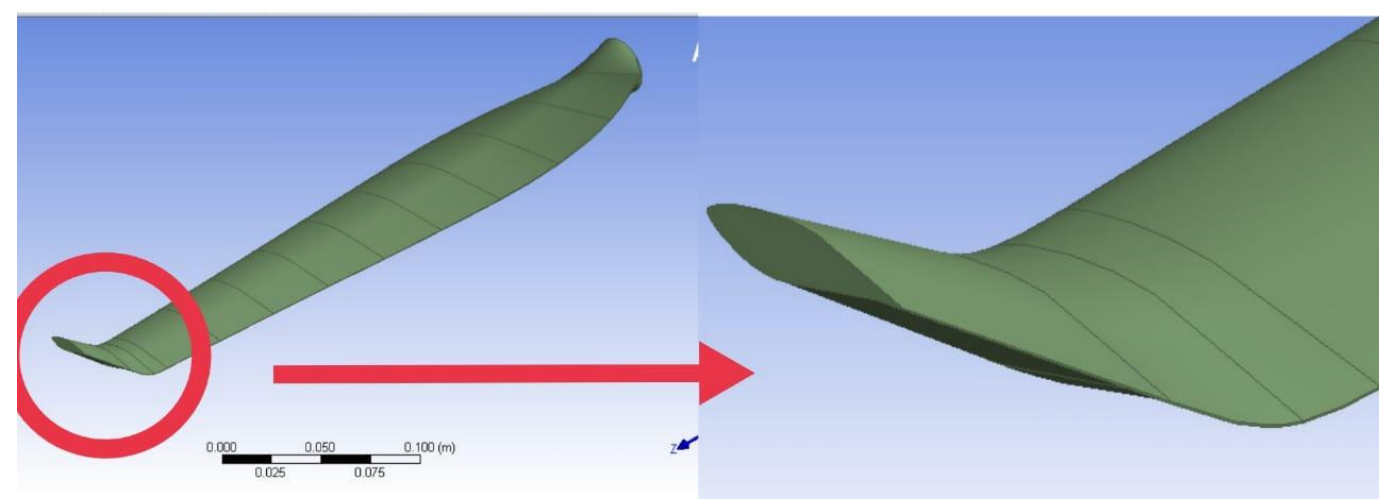

Fig. 3. The constructed blade geometry with winglet by solid works 
The last four parameters are taken in consideration in the design of winglet in this study, depending on the varying of these parameters, twenty different winglet designs have been analyzed. The aerofoil used is same in all the twenty cases, which is $\mathbf{5 8 0 9}$. Based on the previous studies, all winglet designs bent towards the suction side. As indicated in Table 3, the winglet designs from 1 to 5 kept constant at three parameters (cant angle, twist angle and taper ratio), and only winglet Height varied from $4 \%$ to $12 \%$. The winglet designs from 6 to 10 were made at constant three parameters (height, twist angle and taper ratio), and only cant angle varied from $30^{\circ}$ to $70^{\circ}$. The winglet designs from 11 to 15 were made at constant three parameters (height, cant angle and taper ratio), and only twist angle varied from $1^{\circ}$ to $5^{\circ}$, and finally The winglet designs from 16 to 20 were made at constant three parameters (height, cant angle and twist angle), and only taper ratio varied from 0.2 to 1 .

Table 3

Parameters variation of winglet designs

\begin{tabular}{lllll}
\hline $\begin{array}{l}\text { Winglet } \\
\text { Number }\end{array}$ & $\mathrm{H} \% \mathrm{R}$ & $\begin{array}{l}\theta \\
\text { (degrees) }\end{array}$ & $\beta$ & $\wedge$ \\
\hline W1 & $12 \%$ & 50 & 3 & 0.6 \\
W2 & $10 \%$ & & & \\
W3 & $8 \%$ & & & \\
W4 & $6 \%$ & & & \\
W5 & $4 \%$ & & 3 & 0.6 \\
W6 & $8 \%$ & 30 & & \\
W7 & & 40 & & \\
W8 & & 50 & & \\
W9 & & 60 & & \\
W10 & & 70 & & \\
W11 & $8 \%$ & 50 & 1 & \\
W12 & & & 2 & \\
W13 & & & 3 & \\
W14 & & & 5 & \\
W15 & & & 3 & 0.6 \\
W16 & $8 \%$ & 50 & & 0.4 \\
W17 & & & & 0.6 \\
W18 & & & & \\
W19 & & & & \\
W20 & & & & \\
\hline
\end{tabular}

\subsection{CFD Modeling}

CFD model of wind turbine blade has been established using ANSYS FLUENT 18.1. which is the most common software that is used for CFD modelling.

\subsubsection{Computational domain generation}

Since the wind turbine model was asymmetrical along its center of rotation, the three blades were often modeled employing a single blade in a $120^{\circ}$ radial stream tube domain section with periodic faces. The boundary conditions at the front and top planes were set as velocity inlets with incoming free stream air velocity. The rear plane was set as a pressure outlet. The upstream velocity inlet was located 7 times the blade length upstream the rotor blade. The pressure outlet is fixed at atmospheric pressure and located 15 times the blade length downstream of the rotor blade [27]. The computational domain and the blade inside the domain are presented in Figure 4. 


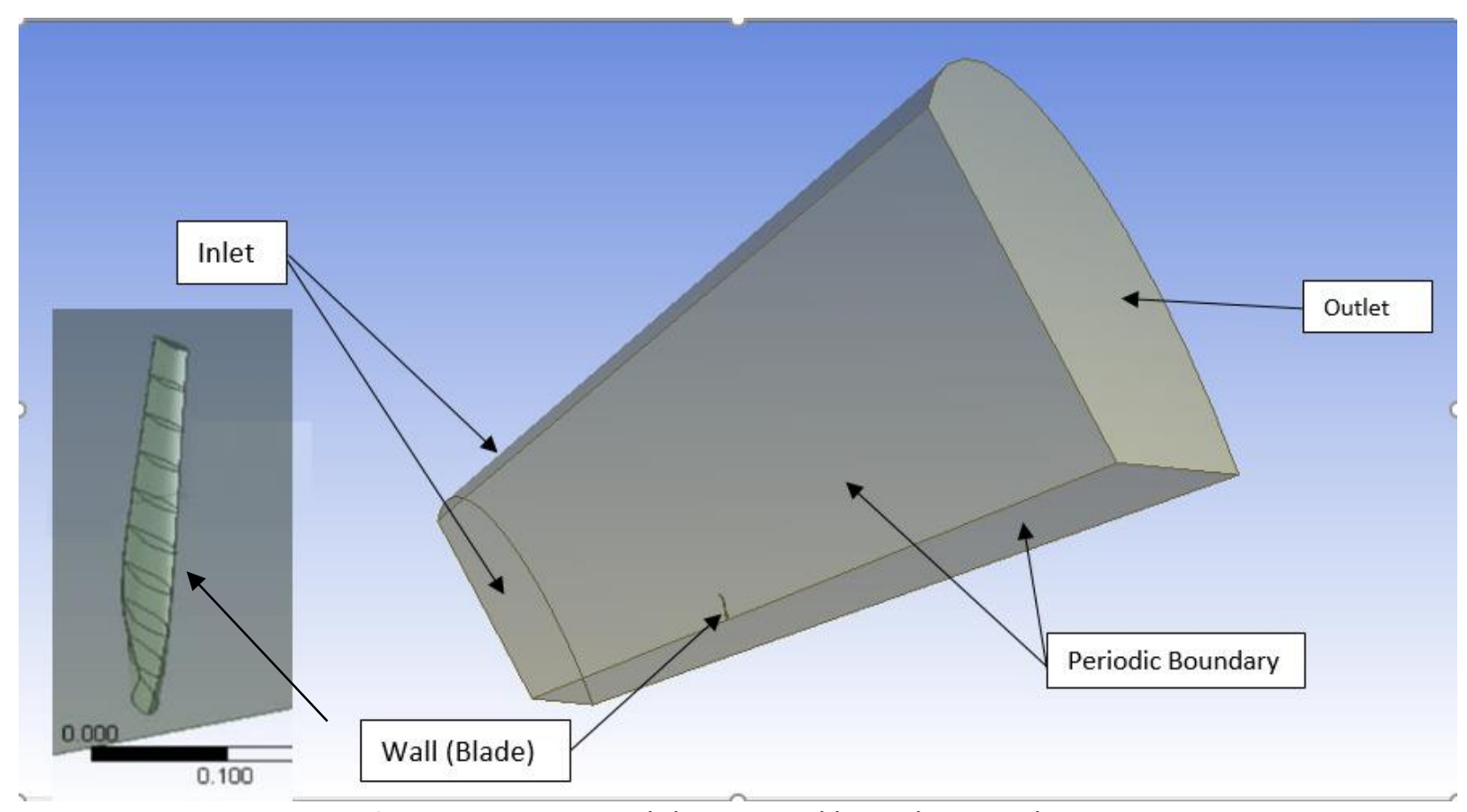

Fig. 4. Computational domain and boundary conditions

\subsubsection{Mesh generation and grid independence studies}

After geometry construction, and before the CFD solution, indicating the fluid volumes and discretizing them by meshing is of great importance. There are different types of mesh methods depending on the discretization elements shapes such tetrahedral, quad-lateral and hexahedral elements shapes. Tetrahedral mesh is used in the present study. Figure 5(a) and Figure 5(b), show the mesh of the fluid domain as well as inflation layer applied at the wall. The mesh density increases in the location of interest and gradually decreases in the far away areas from the blade.

The precision of the CFD solution is influenced by the quality of the mesh grid. Also, the accuracy and percentage error of the simulation result depend on the number of grid elements and element sizes. The current study was checked for grid elements number independence. The simulation was carried out for seven different grids. The results for the seven meshes considered in the grid independence study were presented in Figure 6 . The results have indicated that the mesh with number of elements equal 1.3 million corresponding to power output with the percentage deviation of $3.08 \%$ from the finer grid with 3.0 million elements which costs more computation time. Accordingly, this number, 1.3 million elements is used for all results reported in the current paper. Finer mesh clustering was applied near the blade tip edges to capture the tip vortices. Also, prismatic inflation layers were applied to resolve the boundary layer in near wall region. Fifteen prismatic inflation layers were used on the blade surface, with expansion growth rate of 1.2. The first layer thickness assures dimensionless wall distance $(\mathrm{Y}+)$ less than $5 .(\mathrm{Y}+)$ is a non-dimensional wall distance that is used to guarantee precise modelling of the boundary layer. 


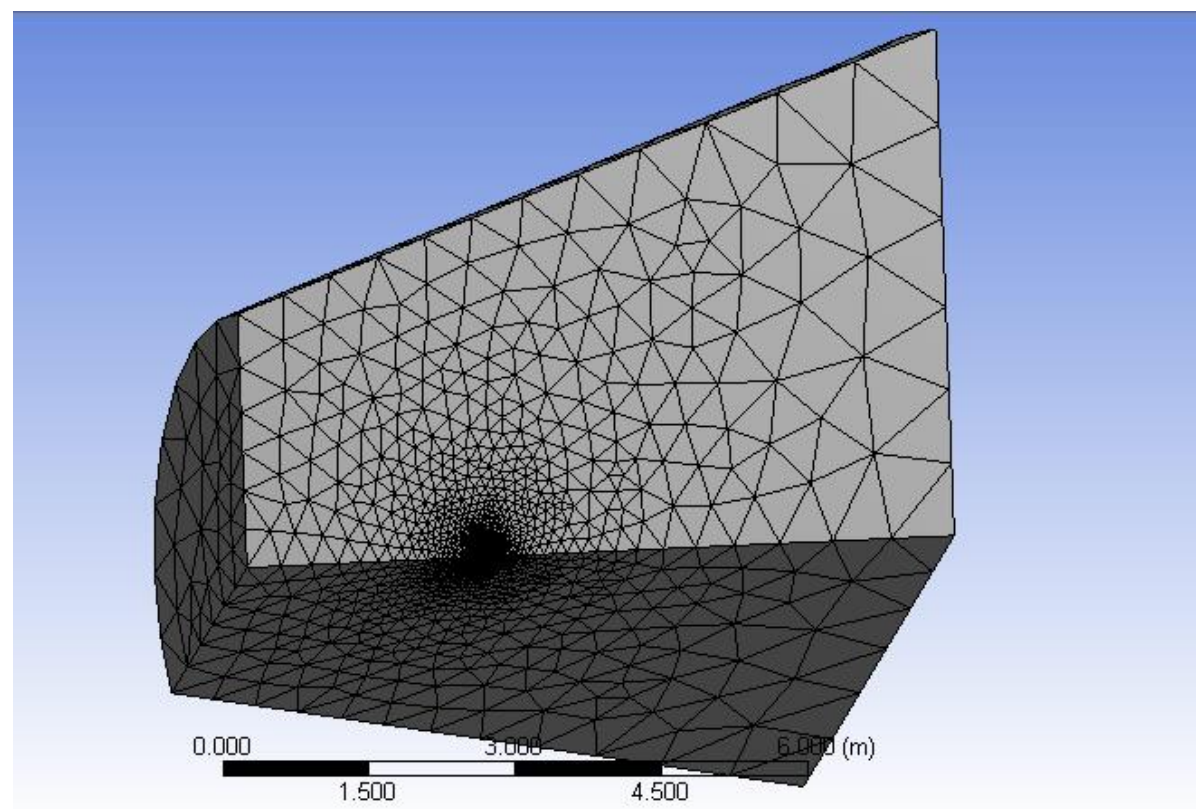

(a)

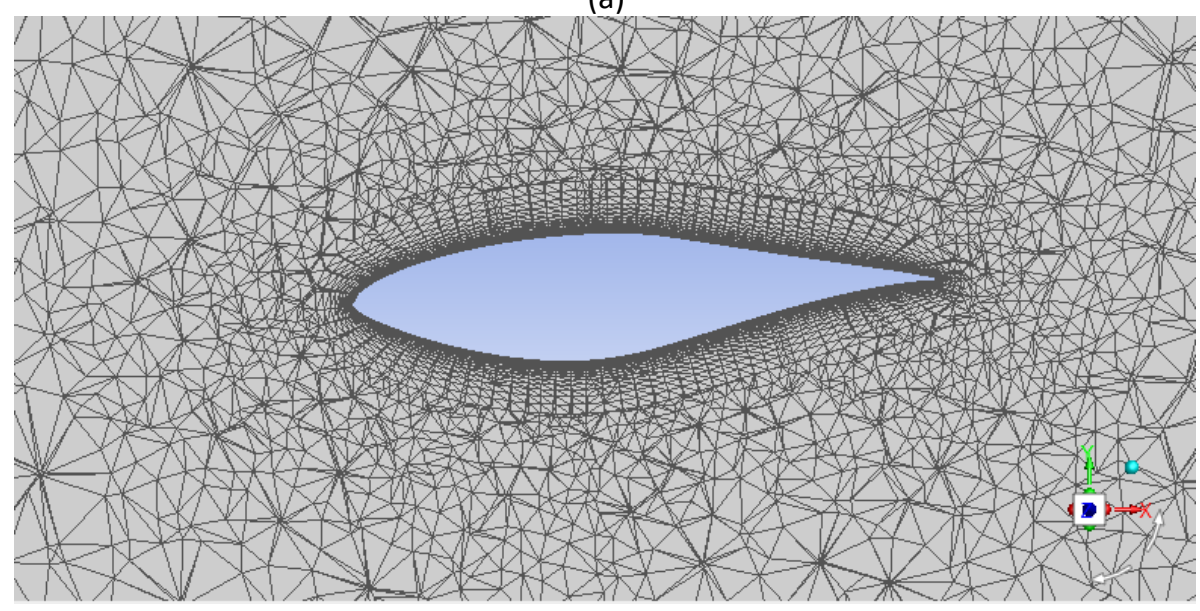

(b)

Fig. 5. (a) Tetrahedral mesh of the computational domain, (b) sectional view for mesh configuration around the blade

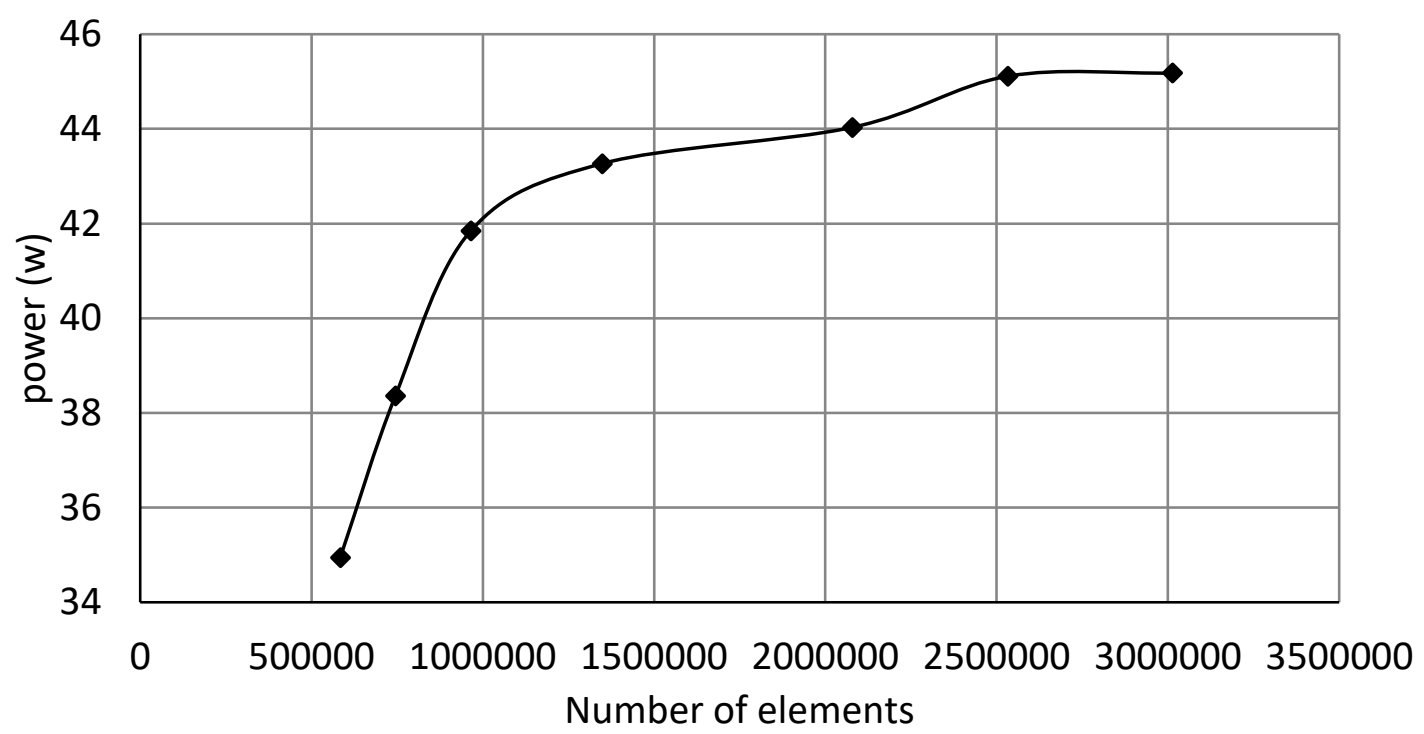

Fig. 6. Grid sensitivity effect on the turbine output power 


\subsubsection{Turbulence model}

The most flows encountered in actual life are turbulent in nature. The turbulence motion flow is mostly rotational which are formed by the viscous effects of boundaries and the fluid separation from the surface The flow characteristics were obtained by solving the steady state Reynolds Averaged Navier-Stokes Equations (RANS) with $k-\omega$ SST (shear stress transport) [28]. The $k-\omega$ SST is a twoequation eddy-viscosity model that uses the turbulence kinetic energy $k$ and also the specific rate of dissipation $\omega$ to predict turbulence. The main advantage of the $k-\omega$ SST model is its precision in predicting the flow behavior of the wall boundary layer. This model was recommended because of its good accuracy in adverse pressure gradient and separating flow [29].

\subsection{Numerical Model Validation}

\subsubsection{Mathematical model}

As mentioned before that the BEM theory used to analyze aerodynamic loads for small wind turbine blades. This method can also estimate the power extracted by the turbine, therefore, to validate the numerical model, the extracted power calculated mathematically using BEM and compared to the extracted power computed using numerical model. The MATLAB software was used in calculation of the total power. The axial induction factor, $\left(a_{i}\right)$, defined as the fractional decrease in wind velocity between the free stream and the turbine plane, is expressed as:

$\mathrm{a}_{i}=\frac{1}{1+\frac{4 f_{i} \times \sin ^{2} \varphi_{i}}{\sigma_{i} \times c_{l} \times \cos \left(\varphi_{i}\right)}}$

Where $\sigma_{i}$ is the solidity ratio which can be defined as the ratio of the planform area of the blade and the swept area of the blade, The solidity ratio,

$\sigma_{i}=Z \times \frac{C_{i}}{2 \pi r_{i}}$

Prandtl tip loss $\mathrm{f}_{\mathrm{i}}$ : which presents a tip loss correction factor

$\mathrm{f}_{\mathrm{i}}=\frac{2}{\pi} \times \cos ^{-1}\left(\mathrm{e}\left(-\frac{z}{2} \times \frac{1-\frac{r_{i}}{R}}{\frac{r_{i}}{R} \times \sin \varphi_{i}}\right)\right)$

Elemental torque,

$\mathrm{dT}_{\mathrm{i}}=\sigma_{\mathrm{i}} \pi \rho \frac{V^{2}\left(1-a_{i}\right)^{2}}{\sin ^{2} \varphi_{i}} \times \mathrm{C}_{\mathrm{L}} \sin \phi_{\mathrm{i}}-\mathrm{C}_{\mathrm{d}} \cos \phi_{\mathrm{i}} \times \mathrm{r}_{\mathrm{i}} \times \mathrm{dr}$

Where $\rho$ density of air, $C_{d}$ drag coefficient, $d r$ radial length of element. The total power from each element is:

$P=z \times \Sigma d T_{i} \times \Omega$ 


\subsubsection{CFD model}

The validation of the current CFD setup including turbulence and geometrical models is accomplished by the comparison with the results of the experimental measurements introduced by NREL (the National Renewable Energy Laboratory). The computation was carried out for the rotor at incoming wind velocity ranging between 6.3 and $17 \mathrm{~m} / \mathrm{s}$. Figure 7 shows a close agreement of the current computations with those of NREL [30]. The results indicated maximum inconsistency up to $3 \%$ between the computed and reference values. This may be explained as result of not considering the friction and power transmission efficiency during the current computations.

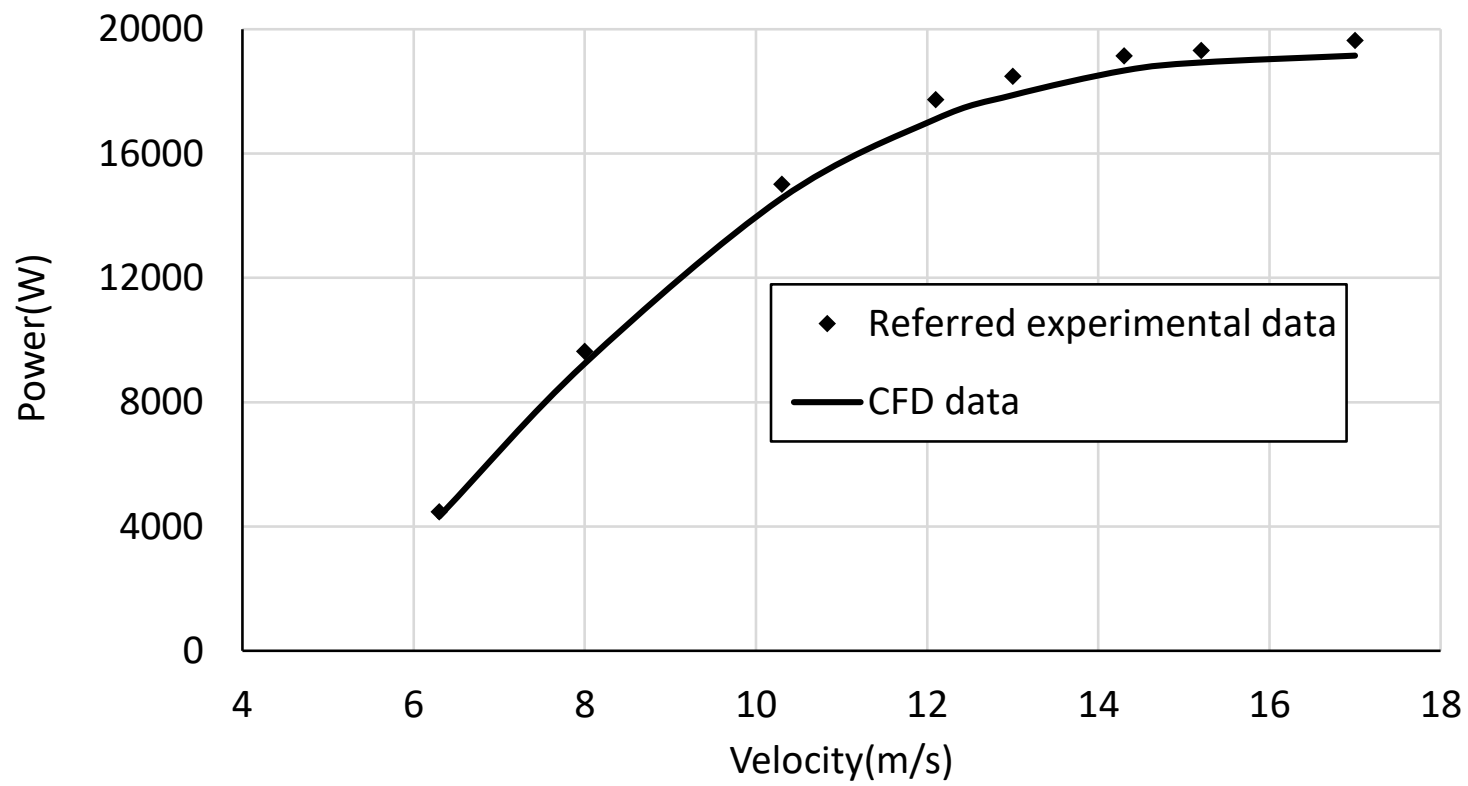

Fig. 7. Comparison between present CFD results and referred experimental values by NREL [30]

\section{Fluid Dynamic Analysis Results}

\subsection{Conventional Blade Performance}

The CFD analysis results such aerodynamic forces and torque that acting in the blade, was displayed after the solution is converged, power developed from the conventional blade can be calculated by using following equation:

$P=Z \times T \times \Omega$

From CFD results, the calculated torque acting on the blade and power generated equals to $0.1668 \mathrm{~N} . \mathrm{m}$, and $45.77 \mathrm{~W}$ respectively. The results indicate a small deviation between mathematical and CFD computed power of $2.88 \%$. The pressure contour and velocity vectors are presented in Figure $8(\mathrm{a})$, which illustrates the effect of tip vortex on the rotor performance. In addition, it presents the velocity vector of the flow transferred from the pressure side to the suction side due to pressure difference. This leads to generation of tip vortices, which responsible for increase in induced drag. The tip vortex can be obviously noticed from the Figure $8(\mathrm{~b})$. The pressure contour in Figure $8(\mathrm{~b})$ obviously illustrates the vortex core location through the dark blue color at the blade tip. On the other hand, the blade with winglet able to reduce the tip vortex effect through shifting the vortex core far from blade tip. 


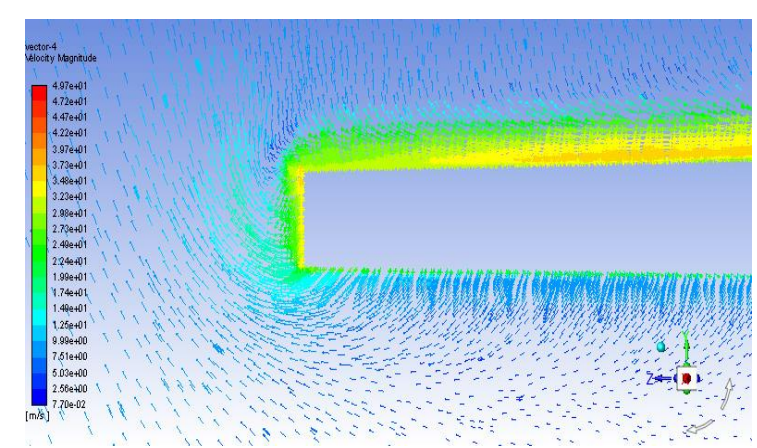

(a)

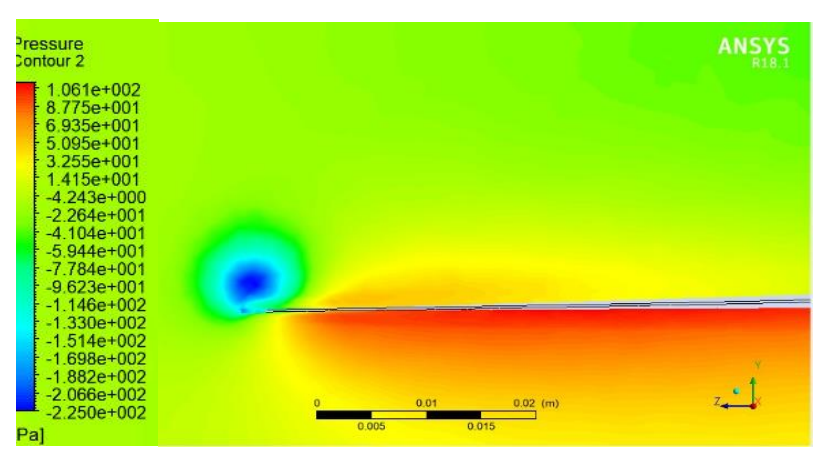

(b)

Fig. 8. (a) Velocity vectors and (b) pressure contour of the conventional blade

\subsection{Effect of Winglet Height on Rotor Performance}

Parametric studies for the winglet geometrical parameter were conducted. Effect of winglet height on the wind turbine performance was studied. Figure 9 shows the five winglet heights from W1 to W5 considered in the study $(4,6,8,10$, and $12 \% R)$. The determination of varying winglet height is to reduce to a variant level the tip flow from high pressure side to low pressure side at tip section of the blade. The increment of winglet height is limited to corresponding increment in drag force penalty. The power increment was calculated with different winglet height while the cant angle, twist angle and taper ratio are kept equal $50^{\circ}, 3^{\circ}$ and 0.6 respectively. The power increased up to $28.7 \%$ corresponding to winglet height equal $10 \% \mathrm{R}$. Increasing winglet height over $10 \% \mathrm{R}$ affected the rotor performance by increasing the drag force and as result reduces the consumed power

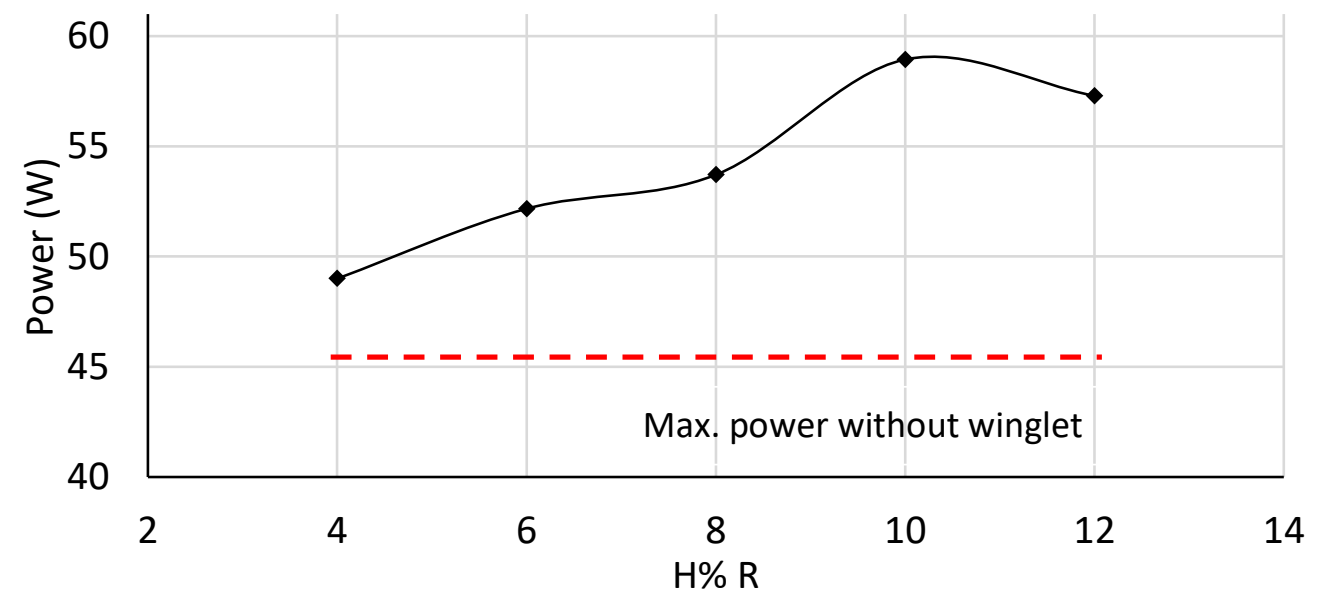

Fig. 9. Variation of power with winglet heights

\subsection{Effect of Cant Angle on Rotor Performance}

The effect of cant angle were investigated in order to improve the aerodynamics performance through reducing the induced drag, which lead to power increment. The blade with winglet with cant angles of 30,40,50, 60 and 70 degrees were studied at winglet height, twist angle and taper ratio of $8 \% \mathrm{R}, 3^{\circ}$, and 0.6 respectively, represented by the designs from $\mathrm{W} 6$ to $\mathrm{W} 10$ in Table 3 . The results indicated a power reduction with cant angle increase. But the design case of W10 at cant angle of 70 degrees achieves power of $50.08 \mathrm{~W}$ more than that of conventional blade without winglet by $10.55 \%$. Figure 10 presents the variation of power with winglet cant angle. Where the design case of W6 at cant angle of 30 degrees achieves power increment of $30 \%$ enhancement. The effect of winglet can 
obviously have noticed in Figures $11(\mathrm{a})$ and Figure 11(b). It shows the velocity vectors and pressure contour of the W6 at cant angle of 30 degrees, where the vortex core at tip of the winglet is weaken compared with conventional blade without winglet at Figure $8(\mathrm{~b})$. The figure shows vortex dissipation far away from blade tip, which Confirms the positive gain from adding winglet.

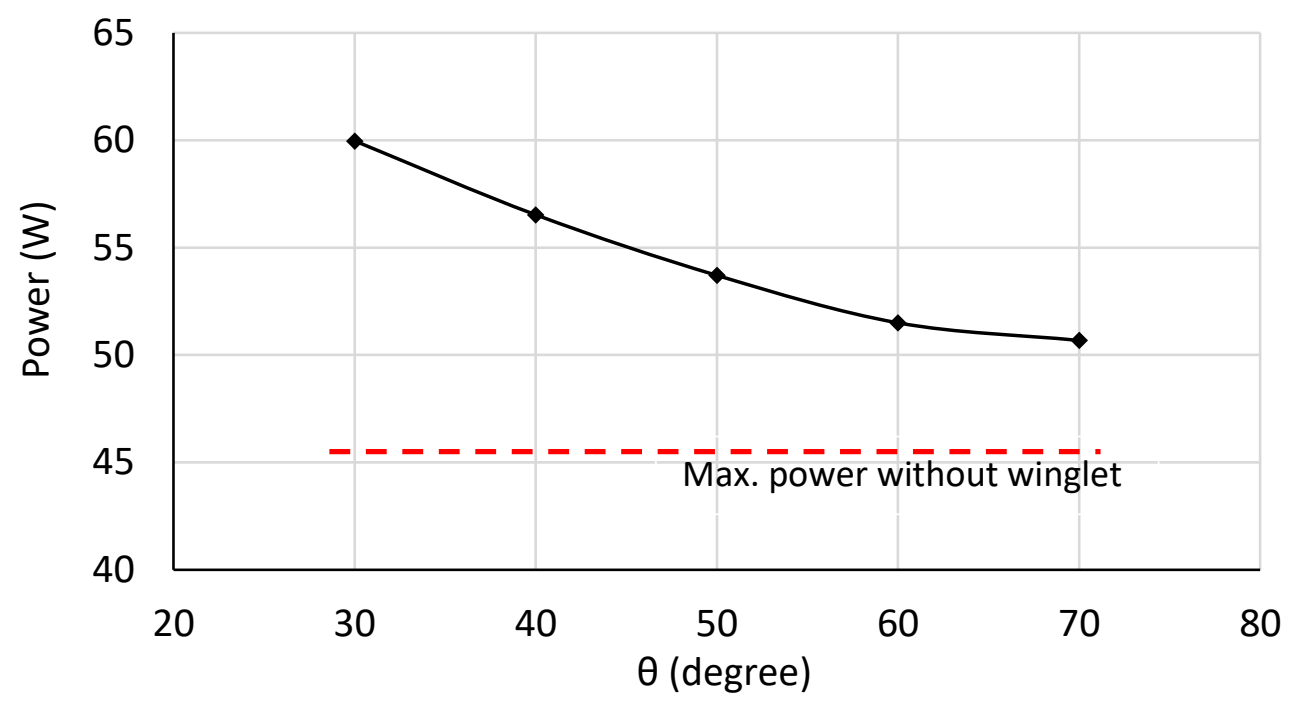

Fig. 10. Variation of power with winglet cant angle

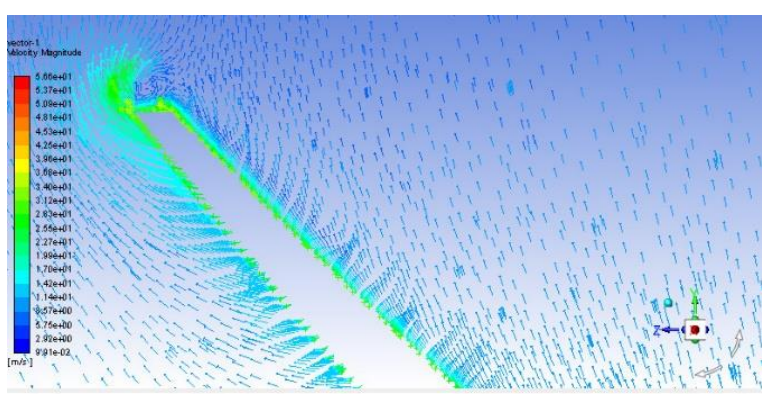

(a)

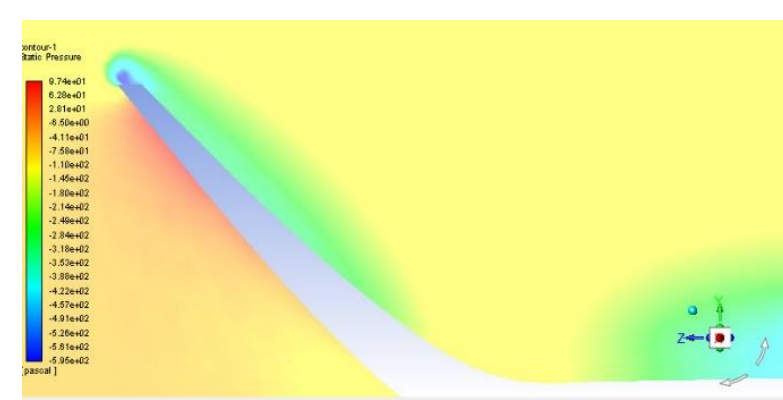

(b)

Fig. 11. (a) Velocity vectors and (b) pressure contour of blade with winglet

\subsection{Effect of Twist Angle on Rotor Performance}

The twist angle directly affects the angle of attack of the winglet with respect to incoming flow. The power calculated at different winglet twist angles with winglet height, cant angle and taper ratio are equal $8 \% R, 50^{\circ}$ and 0.6 respectively. Little dependence on winglet twist was observed according to Figure 12. 


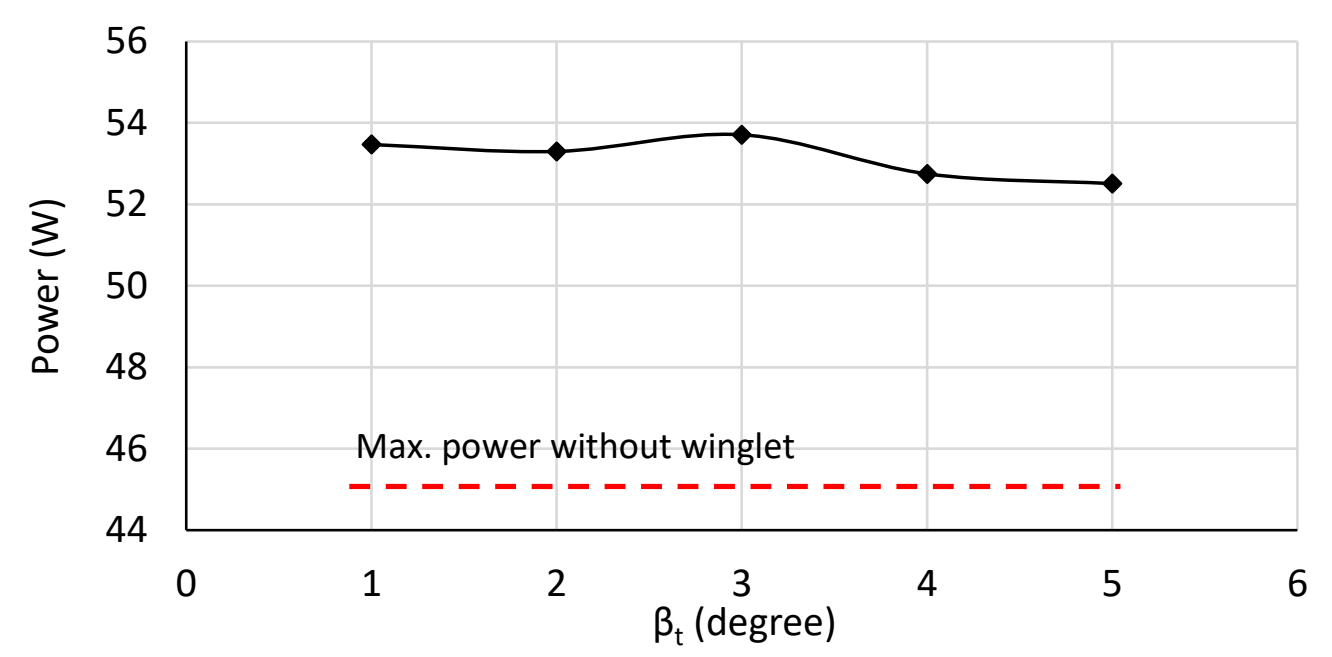

Fig. 12. Variation of power with winglet twist angle

\subsection{Effect of Taper Ratio on Rotor Performance}

Taper ratio is the ratio of winglet tip to root chord lengths. The effect of taper ration was studied with winglet height, cant angle and twist angle are kept equal $8 \% R, 50^{\circ}$ and $3^{\circ}$ respectively. It is one of the geometric parameters, which directly affect three-dimensional drag and lift coefficients. Figure 13 presents the variation of power with winglet taper ratio. It could be inferred that there is a certain winglet taper ratio, which corresponding to minimum drag coefficient and maximum power augmentation. W 16 with taper ratio 0.2 gives the minimum percentage in power increased, just only $2 \%$ increasing in power. Increasing the taper ratio up to 0.8 increased the generated power by reducing the tip vortices intensity near the tip region.

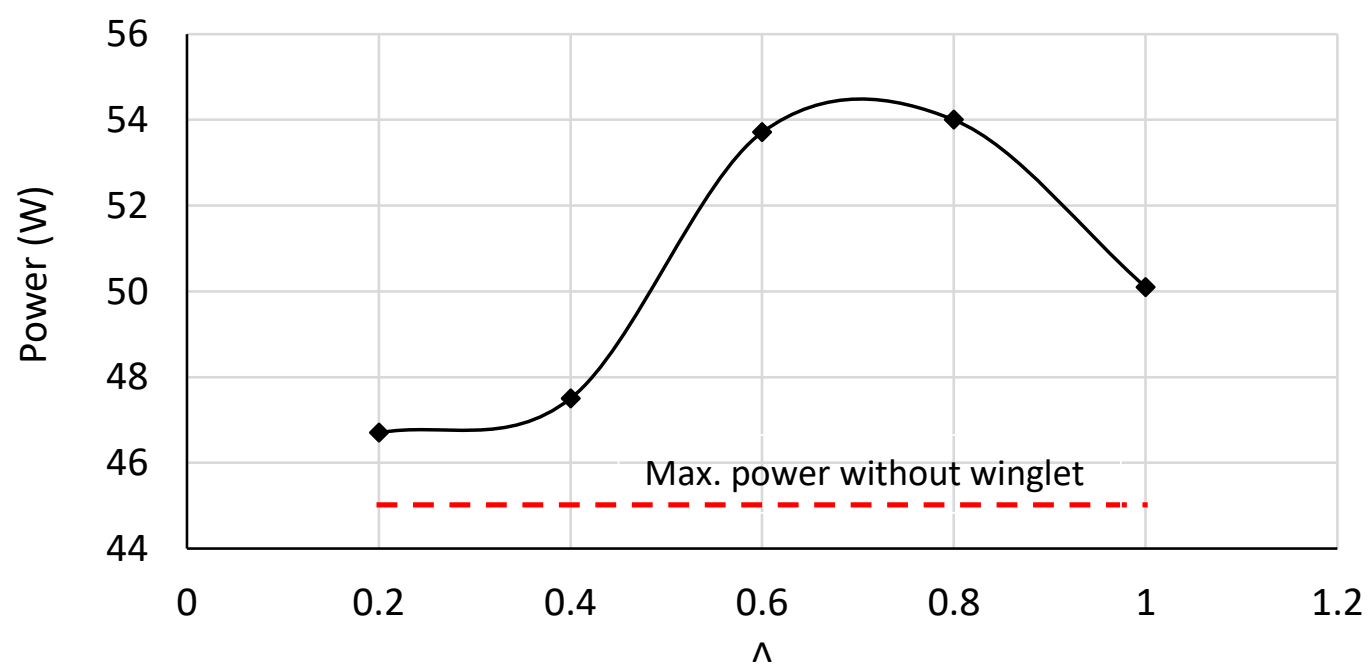

Fig. 13. Variation of power with winglet taper ratio 


\subsection{Effect of Winglet on Pressure Coefficient}

Figure 14 present distribution of pressure coefficient over the blade cross section near the tip. The comparison is done between the blade without winglet at the design conditions $(\mathrm{V}=8 \mathrm{~m} / \mathrm{s}$ \& $\omega=91.43 \mathrm{rad} / \mathrm{s}$ ), and the blade with winglet at the design at the optimum winglet parameters; $\mathrm{H}=$ $8 \% R, \theta$ of $30^{\circ}, \beta$ of $3^{\circ}$ and $\Lambda$ of 0.6 . The increases in pressure coefficient are observed with sections radius ratio starting from $r / R=0.85$. It is obvious that at the adjacent to the blade tip, the pressure difference increases, therefore that is a conclusive proof that adding winglet accomplishment in separating the tip vortex and pushing it away from the blade.

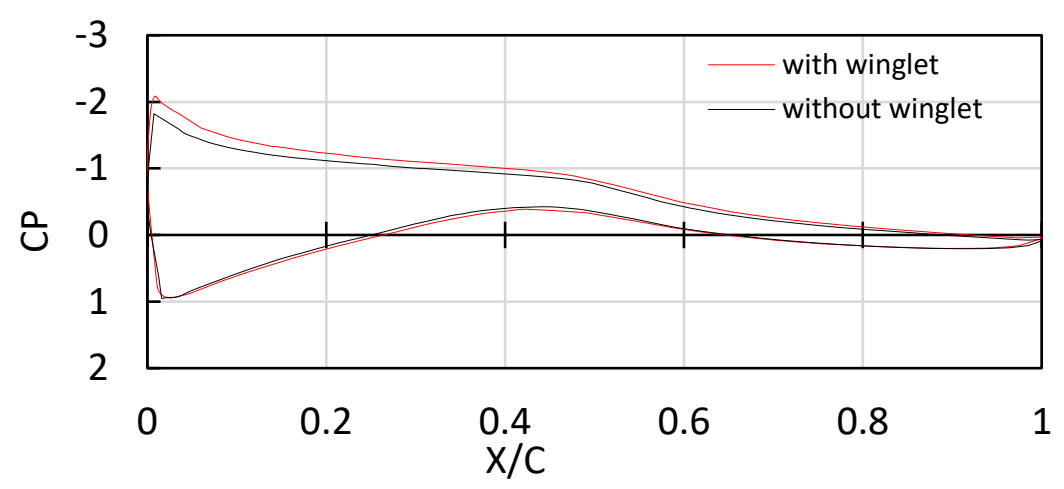

(a)

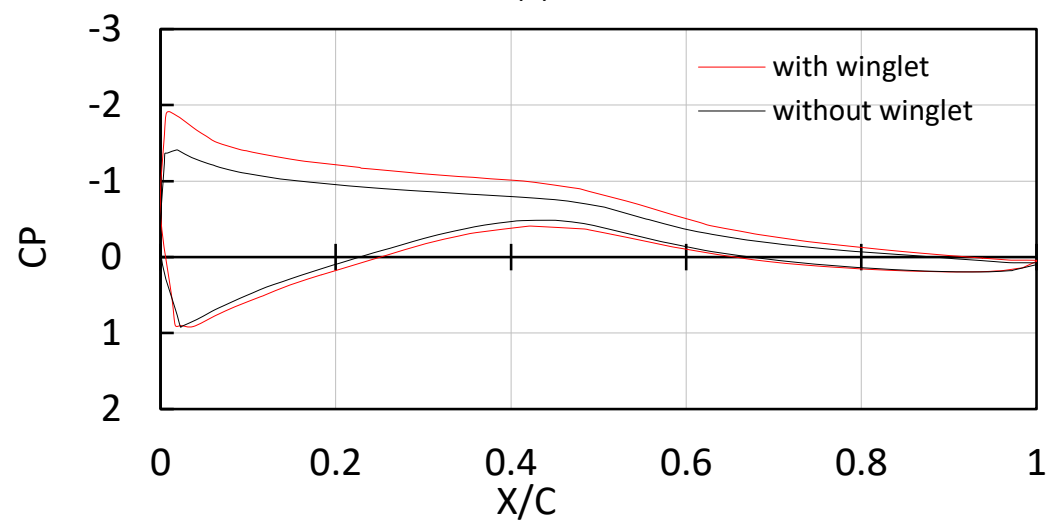

(b)

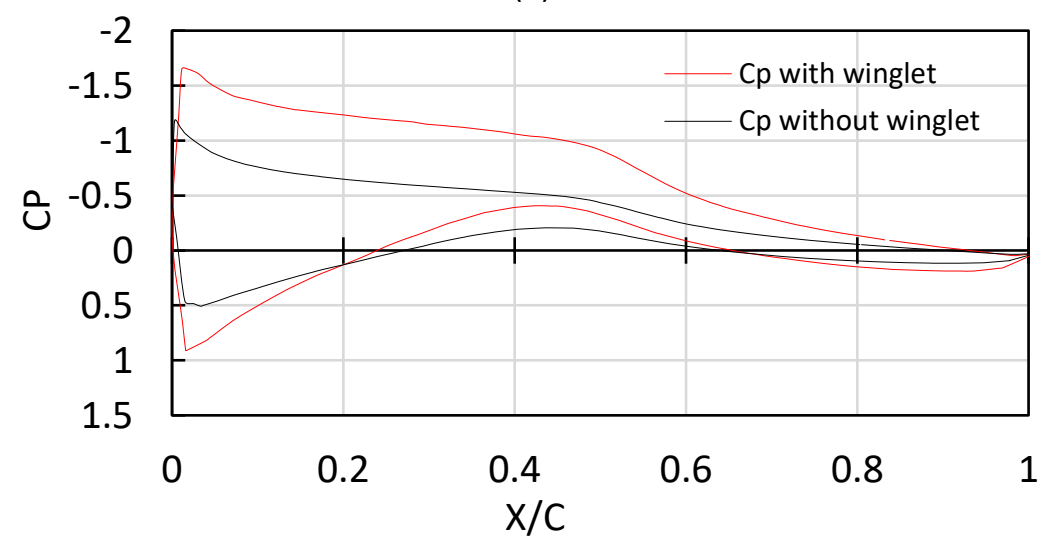

(c)

Fig. 14. Pressure coefficient distribution (A) $r / R=0.85$, (B) $r / R=0.95$, and $(C) r / R=1.0$ at $V=8 \mathrm{~m} / \mathrm{s}$ 


\section{Mathematical Correlation Results}

The turbine power depends on cant angle $(\vartheta)$, winglet height $(H)$, twist angle $(\beta)$, and taper ratio $(\Lambda)$. By the results of the numerical simulation, the least squares method is used to calculate the mathematical correlation coefficient. This fitted mathematical correlation is used in predicting the turbine power for any winglet configuration with $\$ 809$ airfoil can be expressed by:

$P=(94.0889) \times \frac{H^{0.1488} \times \Lambda^{0.0944}}{\theta^{0.21} \times \beta^{0.0093}}$

This mathematical correlation is useful in the prediction of the turbine power at any winglet configuration. Table 4 shows a comparison between the CFD results and mathematical correlation response. Figure 15 and Figure 16 show the predicted effect of the cant angle and winglet height on the turbine power at different taper ratios and twist angles. The turbine power increases with increasing the winglet height. On the other hand, the turbine power decreases with increasing the cant angle. While the twist angle and taper ratios has relatively slight effect.

Table 4

Comparison between the CFD results and mathematical correlation response

\begin{tabular}{lllllll}
\hline $\mathrm{H}(\% \mathrm{R})$ & $\vartheta$ (degrees) & $\mathrm{B}$ (degrees) & $\wedge$ & $\begin{array}{l}\text { CFD } \\
\mathrm{P}(\text { watt) }\end{array}$ & $\begin{array}{l}\text { Math. Correlation } \\
\text { response (watt) }\end{array}$ & Error (\%) \\
\hline $12 \%$ & 50 & 3 & 0.6 & 57.29 & 59.2 & 3.2 \\
$10 \%$ & & & & 58.94 & 55.73 & -5.8 \\
$8 \%$ & & & 53.71 & 53.18 & -1.0 \\
$6 \%$ & & & 52.17 & 51.18 & -1.9 \\
$4 \%$ & & & 49 & 49.55 & 1.1 \\
$8 \%$ & 30 & 3 & 0.6 & 59.97 & 47.97 & -25 \\
& 40 & & & 56.53 & 50.95 & -11 \\
& 50 & & & 53.71 & 53.18 & -1.0 \\
& 60 & & & 51.5 & 54.98 & 6.3 \\
& 70 & & & 50.68 & 56.49 & 10.3 \\
$8 \%$ & 50 & 1 & 0.6 & 53.47 & 53.72 & 0.5 \\
& & 2 & & 53.3 & 53.38 & -1.0 \\
& & 3 & & 53.71 & 53.18 & 0.5 \\
& & 4 & & 52.75 & 53.04 & 0.8 \\
& & & & 52.51 & 52.93 & 2.6 \\
$8 \%$ & 5 & 3 & 0.2 & 46.7 & 47.94 & -1.2 \\
& 50 & & 0.4 & 47.5 & 51.18 & 1.2 \\
& & & 0.6 & 53.7 & 53.18 & 10.2 \\
\hline
\end{tabular}




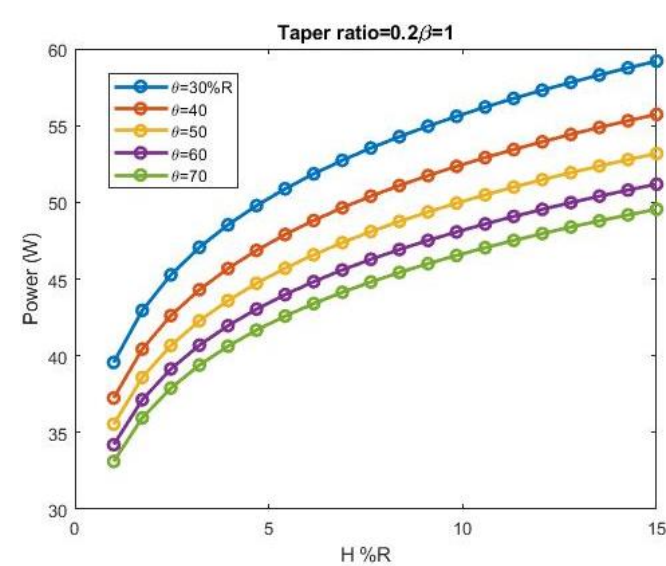

(a)

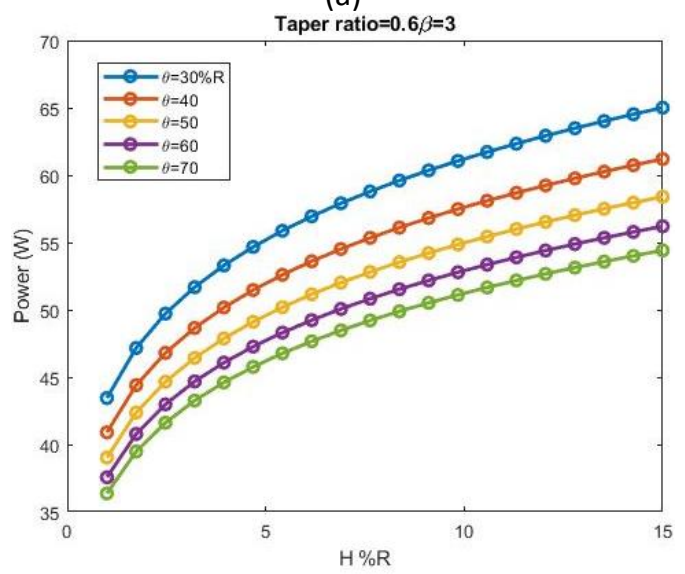

(c)

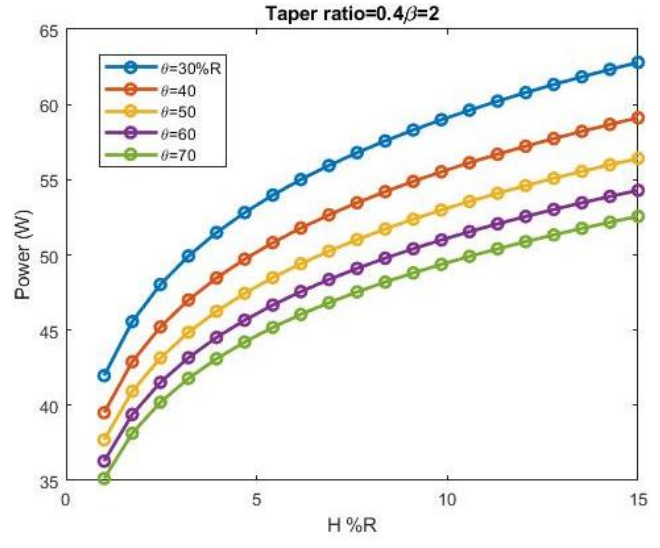

(b)

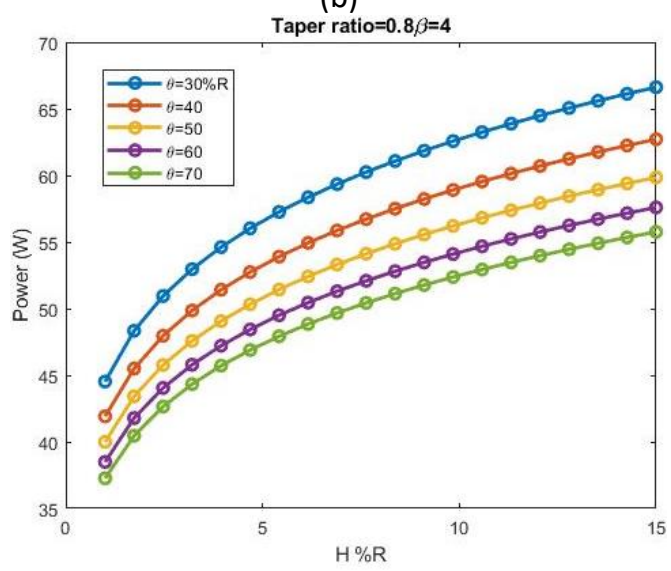

(d)

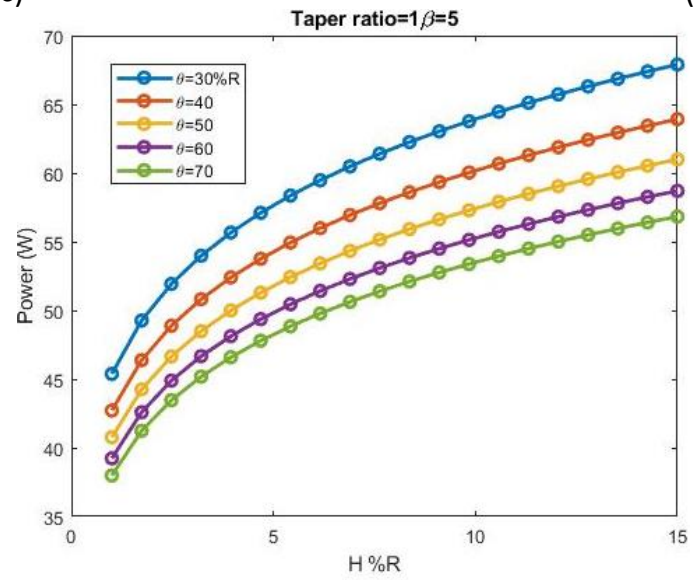

(e)

Fig. 15. Effect of winglet height and cant angle on the turbine power at variable taper ratio and twist angle 


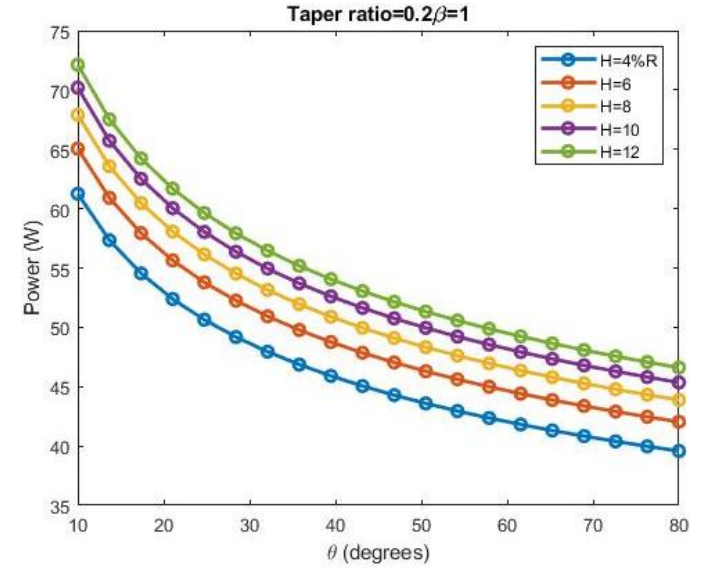

(a)

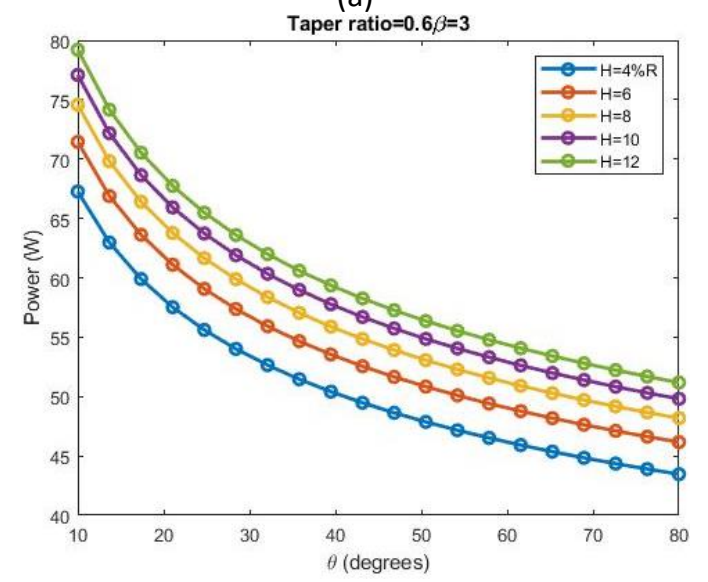

(c)

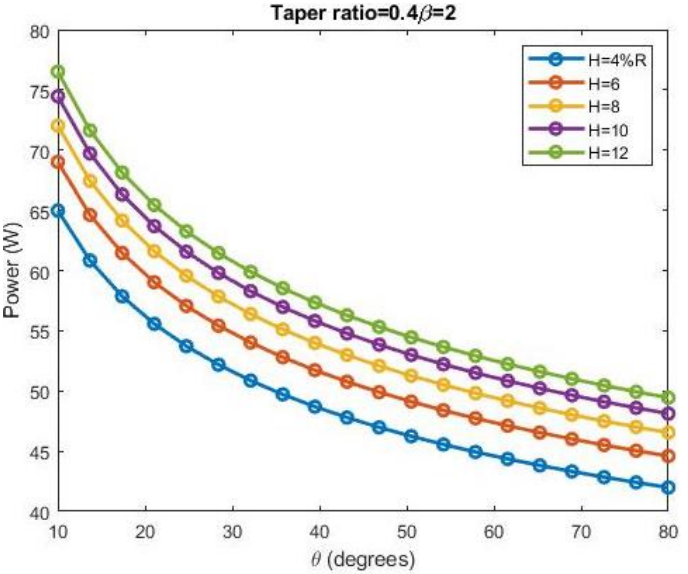

(b)

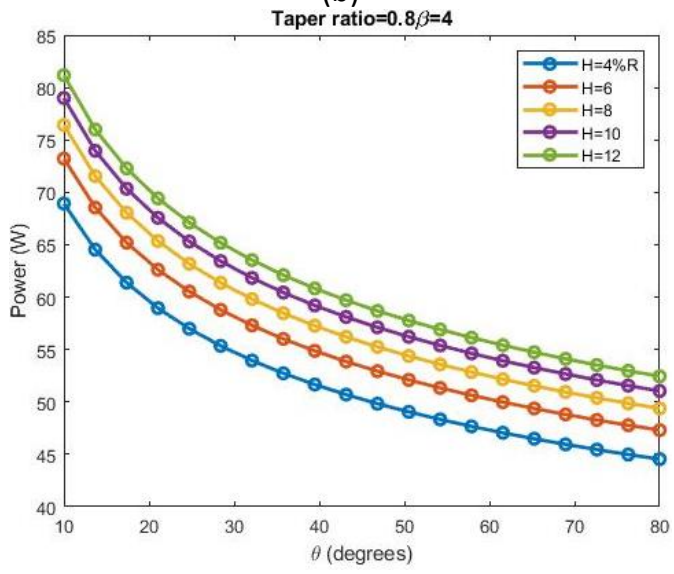

(d)

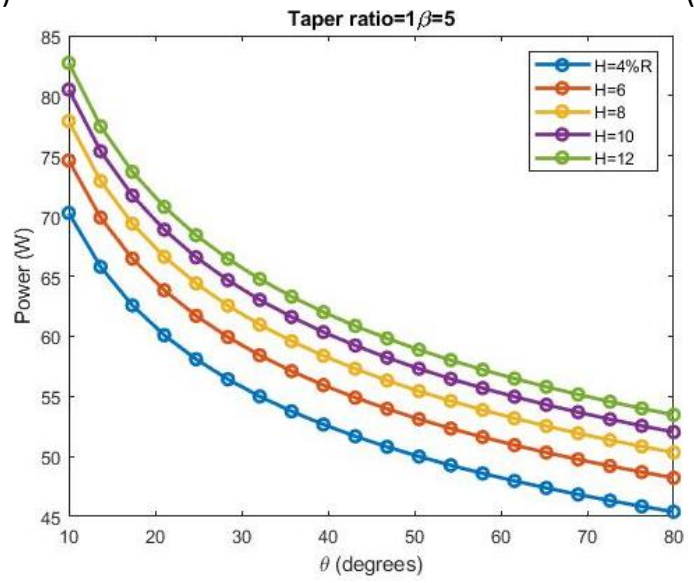

(e)

Fig. 16. Effect of cant angle and winglet height on the turbine power at variable taper ratio and twist angle

\section{Structure Analysis Result}

\subsection{Material Selection}

There are many articles focusing on dynamic modeling response of the wind turbine blades. The current paper studies the effect of winglet on the HAWT blades, the aerodynamic loads are calculated using CFD and blade structural responses are determined using FEA. The coupling strategy is based on a strategy, in which the computed aerodynamic loads from CFD are mapped to FEA modelling as load boundary conditions. The materials used for blade construction should combine the necessary 
structural properties namely high strength to weight ratio, fatigue life and stiffness with low cost. It should be easy to fabricate into the desired aerodynamic shape and it should be low density and excellent corrosion resistance [31,32].

The wind turbine blades were built from fiber reinforced polymer composites such as $E$ glass epoxy and carbon fiber composites. Carbon fibers represent a very promising alternative to the traditional E-glass fibers. Carbon fibers have a higher cost than $\mathrm{E}$ glass fiber. It was then recommended combination of carbon and E-glass fibers as a promising solution. This has made combination of higher stiffness (due to carbon fibers) with limited cost increase [33]. In comparing aluminum alloy with composite materials (epoxy e glass and carbon fiber) for wind turbine blade manufacturing for the same loading conditions. A $15 \%$ reduction in weight can be obtained by replacing an aluminum turbine blade with a composite turbine blade [34]. Ravikumar et al., [35]. recommended that aluminum alloy for hub design is safe for 20 years' time of wind turbine life time because of the longer fatigue life of aluminum alloy. In general, glass fiber reinforced composite material became the preferred material for wind turbine rotor blades [36,37].

The CFD modeling process was consisted of four main steps starting with the generation of geometry and therefore, the computational domain, then mesh generation, setting up the boundary conditions of the problem, and finally solving and post process of the results. The aerodynamics load was mapped to the Finite Element Analysis (FEA) modeling as load boundary conditions. The structure analysis depends on the FEA that is capable of analyzing the expanded stress distributions among every layer of composite blade structure. The FEM method will be used to analysis the stresses of the wind turbine blade, the analysis will be carried out by using ANSYS Static Structural module. The FEA study was conducted using epoxy E-glass unidirectional (EEGUD, Properties are presented in Table 5.

Table 5

Properties of EEG (UD)

\begin{tabular}{lllllllllll}
\hline Properties & $\mathrm{E}(\mathrm{X})$ & $\mathrm{E}(\mathrm{Y})$ & $\mathrm{E}(\mathrm{Z})$ & $\mathrm{u}(\mathrm{XY})$ & $\mathrm{u}(\mathrm{YZ})$ & $\mathrm{u}(\mathrm{XZ})$ & $\begin{array}{l}\mathrm{G}(\mathrm{XY}) \\
(\mathrm{Mpa})\end{array}$ & $\begin{array}{l}\mathrm{G}(\mathrm{YZ}) \\
(\mathrm{Mpa})\end{array}$ & $\begin{array}{l}\mathrm{G}(\mathrm{XZ}) \\
(\mathrm{Mpa})\end{array}$ & $\begin{array}{l}\text { Density } \\
\left(\mathrm{Kg} / \mathrm{m}^{3}\right)\end{array}$ \\
\hline Value & 45000 & 10000 & 10000 & 0.3 & 0.4 & 0.3 & 5000 & 3846.2 & 5000 & 2000 \\
\hline
\end{tabular}

\subsection{Structural Analysis of Rotor Blade without Winglet}

The aerodynamic pressures on the blade obtained from CFD modelling were applied to the FEA model as load boundary conditions. Having define the materials, geometry, mesh, boundary conditions and aerodynamic loads, the different types of structural analysis, such as static stresses analysis and deformations have performed. The study performed under the design conditions at wind speed $8 \mathrm{~m} / \mathrm{s}$ and angular velocity $91.43 \mathrm{rad} / \mathrm{s}$. Figure 17 represents the total deformation and static stresses that act on the rotor blade. It observed from the Figure 17(a) that the maximum deformation is about to $0.1285 \mathrm{~mm}$ at the tip of blade due to rotation and airflow around the tip, which result in high loads near tip. The minimum deformation at the root of blade due to the fixation at the hub, also it can be noticed from Figure 17(b) that maximum stresses equal $6.32 \mathrm{Mpa}$. 


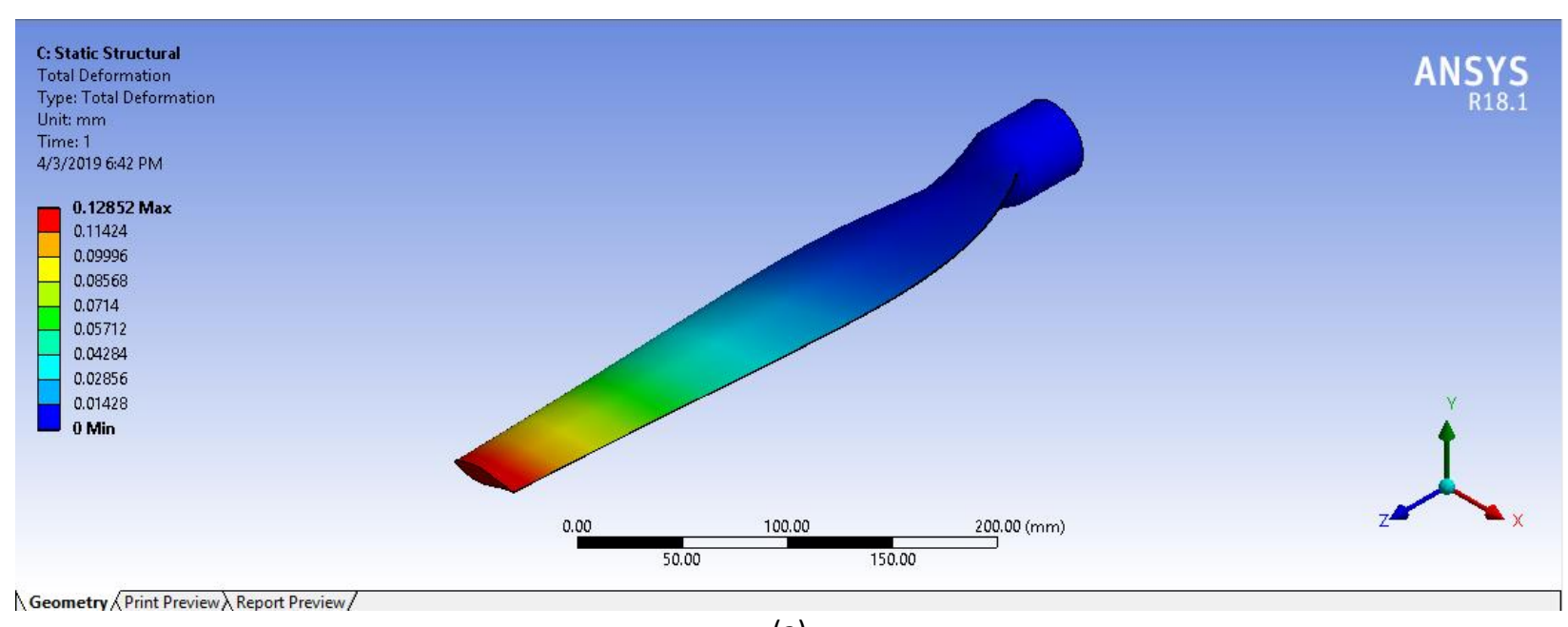

(a)

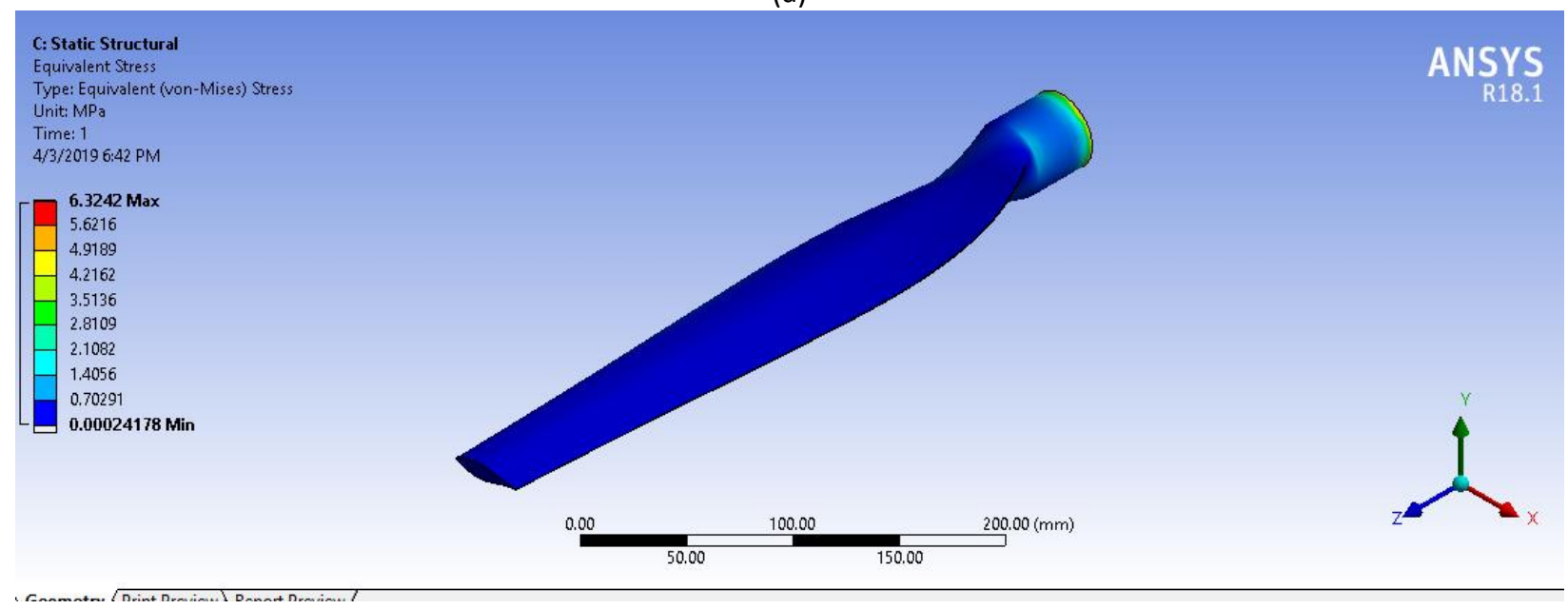

(b)

Fig. 17. The deformation and stresses distribution of EEGUD without winglet

\subsection{Structural Analysis of Rotor Blade with Winglet}

The structural analysis for the blade with winglet is similar in sequence discussed before for conventional blade. The structural analyses performed for the case corresponding to highest power with $\mathrm{H}=8 \% \mathrm{R}, \theta=30^{\circ}, \beta=3^{\circ}$ and $\Lambda=0.6$. Figure 18 represents the total deformation and static stresses on rotor blade. The maximum deformation transferred from the blade tip to the winglet tip due to transition of tip vortex. The maximum deformation equals $0.37 \mathrm{~mm}$. The maximum stress equals 16.37 $\mathrm{Mpa}$ at the blade root. In addition, there is a little stress concentration in the region of the bending of winglet. 


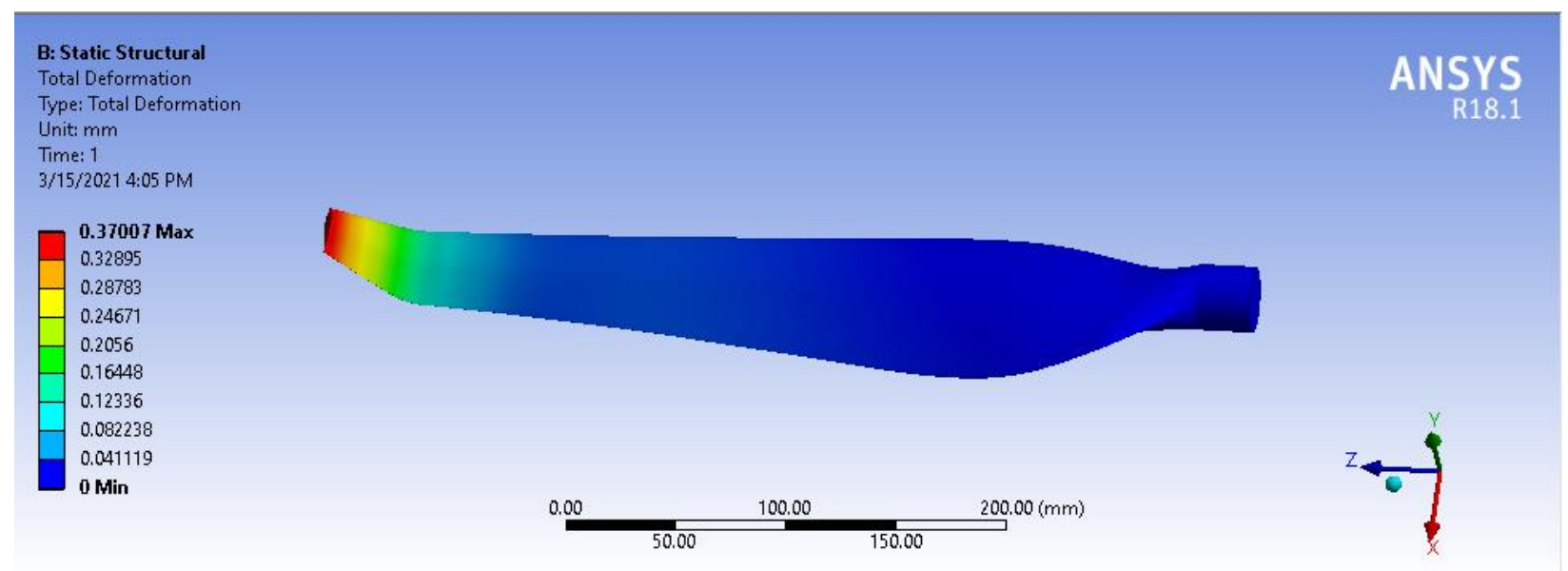

(a)

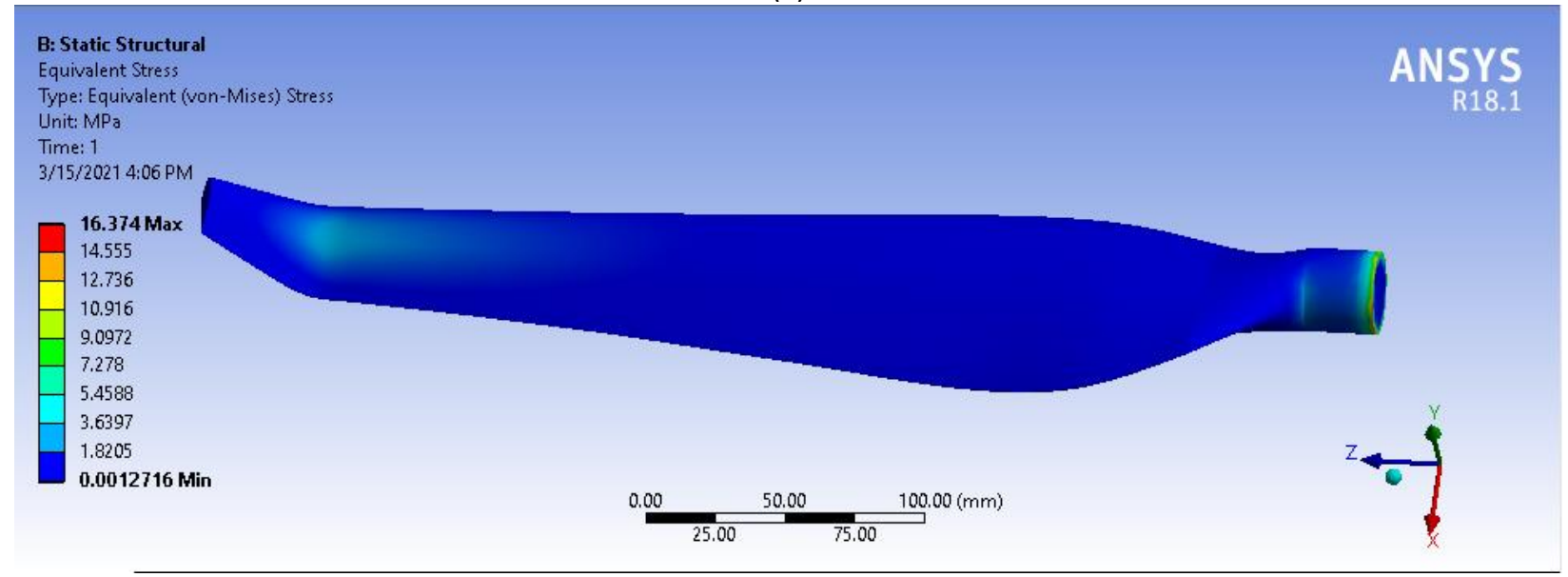

(b)

Fig. 18. The deformation and stresses distribution of EEGUD with winglet

\section{Conclusion}

The numerical results of the HAWT with winglet discussed during current study. The numerical analysis conducted using ANSYS 18.1 software. The paper presents a parametric study for winglet height ( $4 \%$ to $12 \% \mathrm{R})$, cant angle $\left(30^{\circ}\right.$ to $\left.70^{\circ}\right)$, twist angle $\left(1^{\circ}\right.$ to $\left.5^{\circ}\right)$, and taper ratio $(0.2$ to 1$)$ at wind speed $8 \mathrm{~m} / \mathrm{s}$. The analysis aimed to investigate the effect of winglet on the aerodynamic performance of the wind turbine, and its effect on the structure of rotor blade using epoxy E-glass unidirectional as the main material. The main conclusions summarized as

i. Respectable agreement of the current CFD model (with maximum deviation equal $3 \%$ ) in comparison with the results of the experimental measurements introduced by NREL (the National Renewable Energy Laboratory).

ii. The results globally showed that adding winglet to the conventional HAWT blade increases the generated power approximately up to $30 \%$ depending on winglet geometry.

iii. The winglet has reduced the effect of wingtip vortices, which has produced due to pressure difference between lower and upper blade surfaces.

iv. It concluded that the most important two parameters in the design of winglet were the winglet height and cant angle

v. The mechanical power decreases as the cant angle increases.

vi. The mechanical power increases as the winglet height increase to a specific limit then decreases due to extra winglet height, which increases the induced drag. 
vii. The optimum key parameters for winglet design that gives maximum power are corresponding to winglet height of $8 \%$, cant angle of $30^{\circ}$, twist angle of $3^{\circ}$, and taper ratio of 0.8 , at wind velocity of $8 \mathrm{~m} / \mathrm{s}$.

viii. The mathematical correlation is established and being used in predicting the turbine power for any winglet configuration with $\mathbf{8 0 9}$ airfoil which is expressed as

$$
P=(94.0889) \times \frac{H^{0.1488} \times \Lambda^{0.0944}}{\theta^{0.21} \times \beta^{0.0093}}
$$

ix. The maximum deformation transferred from the blade tip to the winglet tip, however. Its value increased compared to straight blade.

\section{References}

[1] Council, Global Wind Energy. "GWEC. Global wind report. Annual market update 2010." Springer, Berlin, Germany 1, no. 2 (2011): 12-20.

[2] Manwell, James F., Jon G. McGowan, and Anthony L. Rogers. Wind energy explained: theory, design and application. John Wiley \& Sons, 2010. https://doi.org/10.1002/9781119994367

[3] Zhang, Chenyu. "Aerodynamic, structural and aero-elasticity modelling of large composite wind turbine blades." PhD diss., Loughborough University, 2013.

[4] Shen, Wen Zhong, Robert Mikkelsen, Jens Nørkær Sørensen, and Christian Bak. "Tip loss corrections for wind turbine computations." Wind Energy: An International Journal for Progress and Applications in Wind Power Conversion Technology 8, no. 4 (2005): 457-475. https://doi.org/10.1002/we.153

[5] Mattos, Bento, Antonini Macedo, and Durval Silva Filho. "Considerations about winglet design." In 21st AlAA Applied Aerodynamics Conference, p. 3502. 2003. https://doi.org/10.2514/6.2003-3502

[6] Johansen, Jeppe, and Niels N. Sørensen. "Numerical analysis of winglets on wind turbine blades using CFD." In European Wind Energy Congress. Milano: EWEA, 2007.

[7] Johansen, Jeppe, and Niels N. Sørensen. Aerodynamic investigation of winglets on wind turbine blades using CFD. No. RISO-R-1543(EN). Ris $\varnothing$ National Laboratory, Denmark, 2006.

[8] Gupta, Alka, and R. S. Amano. "CFD analysis of wind turbine blade with winglets." In International Design Engineering Technical Conferences and Computers and Information in Engineering Conference, vol. 45042, pp. 843849. American Society of Mechanical Engineers, 2012.

[9] Satwika, Nyoman Ade, Ridho Hantoro, Sarwono Sarwono, and Gunawan Nugroho. "The experimental investigation and numerical analysis on horizontal axis wind turbine with winglet and pitch variations." Engineering Journal 23 , no. 6 (2019): 345-360. https://doi.org/10.4186/ej.2019.23.6.345

[10] Imamura, Hiroshi, Yutaka Hasegawa, and Koji Kikuyama. "Numerical analysis of the horizontal axis wind turbine with wihglets." JSME International Journal Series B Fluids and Thermal Engineering 41, no. 1 (1998): 170-176. https://doi.org/10.1299/jsmeb.41.170

[11] Elfarra, Monier Ali. "Horizontal axis wind turbine rotor blade: winglet and twist aerodynamic design and optimization using CFD." PhD diss., Middle East Technical University, 2011.

[12] Congedo, Paolo Maria, and Maria Grazia De Giorgi. "Optimizing of a wind turbine rotor by CFD modeling." In ANSYS Italy Conference, pp. 16-17. 2008.

[13] Ali, A. "Aerodynamic Optimisation of Small-Scale Horizontal Axis Wind Turbine Blades." School of Aerospace, Mechanical and Manufacturing Engineering RMIT University, Melbourne, Australia, MSc. Thesis (2014).

[14] Gaunaa, Mac, and Jeppe Johansen. "Determination of the maximum aerodynamic efficiency of wind turbine rotors with winglets." In Journal of Physics: Conference Series, vol. 75, no. 1, p. 012006. IOP Publishing, 2007. https://doi.org/10.1088/1742-6596/75/1/012006

[15] Wang, Lin, Robin Quant, and Athanasios Kolios. "Fluid structure interaction modelling of horizontal-axis wind turbine blades based on CFD and FEA." Journal of Wind Engineering and Industrial Aerodynamics 158 (2016): 1125. https://doi.org/10.1016/j.jweia.2016.09.006

[16] Vasjaliya, Naishadh G. "Fluid-Structure Interaction and Multidisciplinary Design Analysis Optimization of Composite Wind Turbine Blade." PhD diss., Embry-Riddle Aeronautical University, 2013.

[17] Kale, Sandip A., Swanand R. Kulkarni, Suraj D. Shravagi, and Ganesh P. Bharambe. "Materials for small wind turbine blades." Renewable Energy: Research, Development and Policies (2015): 43-54. 
[18] Bai, C. J., F. B. Hsiao, M. H. Li, G. Y. Huang, and Y. J. Chen. "Design of $10 \mathrm{~kW}$ horizontal-axis wind turbine (HAWT) blade and aerodynamic investigation using numerical simulation." Procedia Engineering 67 (2013): $279-287$. https://doi.org/10.1016/j.proeng.2013.12.027

[19] Bazilevs, Y., M-C. Hsu, J. Kiendl, R. Wüchner, and K-U. Bletzinger. "3D simulation of wind turbine rotors at full scale. Part II: Fluid-structure interaction modeling with composite blades." International Journal for Numerical Methods in Fluids 65, no. 1-3 (2011): 236-253. https://doi.org/10.1002/fld.2454

[20] Krawczyk, Piotr, Asfaw Beyene, and David MacPhee. "Fluid structure interaction of a morphed wind turbine blade." International Journal of Energy Research 37, no. 14 (2013): 1784-1793. https://doi.org/10.1002/er.2991

[21] Hsu, Ming-Chen, and Yuri Bazilevs. "Fluid-structure interaction modeling of wind turbines: simulating the full machine." Computational Mechanics 50, no. 6 (2012): 821-833. https://doi.org/10.1007/s00466-012-0772-0

[22] Zhang, Jianping, Liang Guo, Helen Wu, Aixi Zhou, Danmei Hu, and Jianxing Ren. "The influence of wind shear on vibration of geometrically nonlinear wind turbine blade under fluid-structure interaction." Ocean Engineering 84 (2014): 14-19. https://doi.org/10.1016/j.oceaneng.2014.03.017

[23] MacPhee, David, and Asfaw Beyene. "Fluid-structure interaction of a morphing symmetrical wind turbine blade subjected to variable load." International Journal of Energy Research 37, no. 1 (2013): 69-79. https://doi.org/10.1002/er.1925

[24] Mattos, Bento, Antonini Macedo, and Durval Silva Filho. "Considerations about winglet design." In 21st AlAA Applied Aerodynamics Conference, p. 3502. 2003. https://doi.org/10.2514/6.2003-3502

[25] Helal, Hesham SM, Essam E. Khalil, Osama E. Abdellatif, and Gamal M. Elhariry. "Aerodynamic Analyses of AircraftBlended Winglet Performance." IOSR J. Mech. Civ. Eng. Ver 13, no. 3 (2016): 2320-334.

[26] Maughmer, Mark D. "Design of winglets for high-performance sailplanes." Journal of Aircraft 40, no. 6 (2003): 10991106. https://doi.org/10.2514/2.7220

[27] Bak, Christian, Peter Fuglsang, Niels N. Sørensen, Helge Aagaard Madsen, Wen Zhong Shen, and Jens Nørkær Sørensen. Airfoil Characteristics for Wind Turbines. No. RISO-R-1065(EN). Risoe National Lab., Roskilde, Denmark, 1999.

[28] Alfonsi, Giancarlo. "Reynolds-Averaged Navier-Stokes Equations for Turbulence Modeling." Applied Mechanics Reviews 62, no. 4 (2009): 040802. https://doi.org/10.1115/1.3124648

[29] Menter, Florianr. "Zonal two equation kw turbulence models for aerodynamic flows." In 23rd Fluid Dynamics, Plasmadynamics, and Lasers Conference, p. 2906. 1993. https://doi.org/10.2514/6.1993-2906

[30] Giguere, P., and Michael S. Selig. Design of a tapered and twisted blade for the NREL combined experiment rotor. No. NREL/SR-500-26173. National Renewable Energy Lab., Golden, CO (US), 1999. https://doi.org/10.2172/750919

[31] Pourrajabian, Abolfazl, Peyman Amir Nazmi Afshar, Mehdi Ahmadizadeh, and David Wood. "Aero-structural design and optimization of a small wind turbine blade." Renewable Energy 87 (2016): $837-848$. https://doi.org/10.1016/i.renene.2015.09.002

[32] Zobaa, Ahmed F., and Ramesh C. Bansal, eds. Handbook of renewable energy technology. World Scientific, 2011. https://doi.org/10.1142/7489

[33] Mishnaevsky, Leon, Kim Branner, Helga Nørgaard Petersen, Justine Beauson, Malcolm McGugan, and Bent F. Sørensen. "Materials for wind turbine blades: an overview." Materials 10, no. 11 (2017): 1285. https://doi.org/10.3390/ma10111285

[34] Subrahmanyam, D. L. V., Kuppili Mohan Krishna, Sammala Rajasekhar, and Y. Dhana Sekhar. "Design And Material Optimization Of Wind Turbine Blade." International Journal of Science Engineering and Advance Technology (IJSEAT) 3, no. 10 (2015): 751-763.

[35] Ravikumar, S., V. Jaswanthvenkatram, and S. Md Sohaib. "Design and analysis of wind turbine blade hub using aluminium alloy AA 6061-T6." In IOP Conference Series: Materials Science and Engineering, vol. 197, no. 1, p. 012044. IOP Publishing, 2017. https://doi.org/10.1088/1757-899X/197/1/012044

[36] Hau, Erich. Wind turbines: fundamentals, technologies, application, economics. Springer Science \& Business Media, 2013.

[37] Christou, Philippe. "Advanced materials for turbine blade manufacture." Reinforced Plastics 51, no. 4 (2007): 2224. https://doi.org/10.1016/S0034-3617(07)70148-0 